\title{
Review of Current Fire Design Rules for Cold-formed Steel Wall Systems
}

\author{
Shanmuganathan Gunalan and Mahen Mahendran
}

\begin{abstract}
Light gauge steel frame (LSF) wall systems are commonly used in industrial and commercial buildings and there is a need for simple fire design rules to predict their load capacities and fire resistance ratings. During fire events, the LSF wall studs are subjected to non-uniform temperature distributions that cause thermal bowing, neutral axis shift and magnification effects and thus resulting in a combined axial compression and bending action on the studs. In this research a series of full scale fire tests was conducted first to evaluate the performance of LSF wall systems with eight different wall configurations under standard fire conditions. Finite element models of LSF walls were then developed, analysed under transient and steady state conditions, and validated using full scale fire tests. Using the results from fire tests and finite element analyses, a detailed investigation was undertaken into the prediction of axial compression strength and failure times of LSF wall studs in standard fires using the available fire design rules based on Australian, American and European standards. The results from both fire tests and finite element analyses were used to investigate the ability of these fire design rules to include the complex effects of non-uniform temperature distributions and their accuracy in predicting the axial compression strength of wall studs and the failure times. The measured time-temperature profiles in the fire tests were used in all the calculations. Suitable modifications were then proposed to the fire design rules. This paper presents the details of this investigation on the fire design rules of LSF walls and the results.
\end{abstract}

Keywords: Fire design rules, Light gauge steel frame walls, Thin-walled steel studs, Nonuniform temperature distributions, Standard fires, Thermal bowing, Neutral axis shift, Buckling, Load ratio. 


\section{Introduction}

Light gauge steel frame (LSF) wall systems are commonly used as load bearing walls in industrial and commercial buildings. They are made of cold-formed and thin-walled steel lipped channel studs and tracks, and are lined with gypsum plasterboards (Figure 1). In these applications LSF wall studs are subjected to axial compression loads, and are protected by plasterboard linings during fire events as these linings not only delay the rapid temperature rise in steel studs but also provide lateral restraints to them. Since LSF walls are usually exposed to fire attack from one side, the thin-walled steel studs are subjected to highly nonuniform elevated temperature distributions during fire events. Such non-uniform temperature distributions will induce complicated structural behaviour of studs involving thermal bowing and magnification effects, non-uniform distribution of strength and stiffness of steel across the cross-section and neutral axis shift (Figure 2). These effects due to non-uniform temperature distributions cause the thin-walled studs to be subjected to combined axial compression and bending actions during fire events. They compound the already complex structural behaviour of thin-walled steel studs involving local and global buckling effects during fires. Therefore it is important that suitable design rules that consider all these effects are available to predict the axial compression strength of LSF wall studs and the failure times of LSF walls under standard fire conditions.

Many researchers [1-8] have proposed fire design rules for LSF walls subjected to nonuniform temperature distributions under standard fire. Klippstein [1] and Gerlich et al. [2] developed their fire design rules based on the AISI design manual while Eurocode 3 was used in references [3-7]. Varying assumptions were used to simplify the design of LSF wall studs subject to the complex behaviour as explained above. In this research a detailed study was undertaken to determine the accuracy of these fire design rules in predicting the load capacity of LSF wall studs subject to non-uniform temperature distributions under standard fire conditions. Alfawakhiri's [8] study based on Canadian cold-formed steel design rules was not considered here.

Ten full scale fire tests of LSF walls were conducted first in this research project to determine the Fire Resistance Rating (FRR) of load bearing LSF wall assemblies under standard fire conditions [9-11]. As shown in Table 1, they included eight different LSF wall configurations. Numerical studies were then undertaken based on suitable finite element models of LSF walls 
[10,12] that had been validated using fire test results [9-11]. Such validated finite element models were used to simulate the behaviour of eight different LSF wall systems under standard fire conditions. Table 1 shows the failure times from fire tests and finite element analyses (FEA).

In this paper, fire design rules proposed in references [1-7] were used to predict the LSF wall stud capacities and failure times under standard fire conditions that were compared with our FEA and fire test results. The measured time-temperature profiles reported in [9-11] were used in this study. The reduction factors for mechanical properties at elevated temperatures were based on the equations proposed in [13]. Fire tests [9-11] showed that plasterboards provided sufficient lateral restraint to LSF wall studs until the failure of studs. This assumption was also used in FEA and was verified using test results. Hence flexural buckling about minor axis and flexural-torsional buckling of studs were not considered in this study.

For comparison purposes some of the parameters in the fire design rules were assumed to be consistent with others. For example, different thermal expansion coefficients were used by previous research [1-7]. However, the values in [14] were used here for comparison purposes. They were also used in our FEA. Previous studies used the design equations available at those times to determine the effective areas of locally buckled wall studs. However, the current equations in European and Australian steel design codes [15-17] were used here.

This paper presents the details and results of this study aimed at investigating the accuracy of available fire design rules in predicting the load capacity of LSF wall studs and the failure times of LSF walls under standard fire conditions. It also includes brief details of the experimental and numerical studies of LSF walls conducted by the authors from which the results were used in this paper.

\section{Experimental Study}

Ten full scale fire tests of LSF walls were conducted first to evaluate the FRR of load bearing LSF wall assemblies [9-11]. One wall specimen was tested to failure under an axial compression load at room temperature while ten wall specimens subjected to a constant axial compression load were exposed to standard fire conditions on one side (Table 1). Conventional LSF wall assemblies lined with single or double layers of plasterboard with or 
without cavity insulation were considered. The insulations used were glass, rockwool and cellulose fibres. A new LSF wall system based on a composite panel was proposed in which the insulation was sandwiched between two plasterboards and this composite panel was used on both sides of the wall frame instead of cavity insulation. This externally insulated LSF wall system was also tested using glass, rockwool and cellulose fibres.

All the steel frames were built to a height of $2400 \mathrm{~mm}$ and a width of $2400 \mathrm{~mm}$. The studs and tracks were fabricated from G500 steel sheets with a nominal base metal thickness of 1.15 $\mathrm{mm}$. The measured yield strength and elastic modulus at ambient temperature were $569 \mathrm{MPa}$ and 213,520 MPa, respectively. The frames consisted of four vertical studs of $90 \times 40 \times 15 \times$ $1.15 \mathrm{~mm}$ lipped channel sections attached to the top and bottom tracks at $600 \mathrm{~mm}$ on centre. Figure 3 shows the test set-up and the test specimen after failure while Table 1 gives the failure times (FRR). Further details of this study and the results are given in [9-11].

\section{Finite Element Analyses}

Detailed numerical studies were undertaken based on suitable finite element models of LSF walls that had been validated using our fire test results [9-11]. Finite element models of load bearing LSF walls under fire conditions were developed in two stages. A suitable model of LSF wall stud subject to an axial compression load with appropriate thermal and structural boundary conditions was considered adequate to simulate the behaviour of LSF walls (Figure 4(a)). The plasterboards do not share any axial compression load applied to the LSF walls and hence they were not included in the model. However, their structural restraining and thermal protection effects were considered. Such a model of LSF wall studs was developed to simulate stud's behaviour under standard fire conditions and to determine the FRR. Figure 2 shows that LSF wall studs are subject to a non-uniform temperature distribution when the wall was subjected to standard fire conditions. This was considered in the finite element modelling of studs. The finite element program ABAQUS was used for both elastic buckling and nonlinear analyses under ambient and fire conditions. Figures 4 (b) and (c) show the behaviour and failure mode of LSF wall studs from FEA. Further details of this numerical study and the results are given in $[10,12]$. 


\section{Predictions of Stud Lateral Deflection}

The LSF wall panel subjected to fire from one side has a non-uniform temperature distribution across the wall (Figure 2(a)), and thus undergoes thermal bowing. This will induce an additional bending moment in the stud and hence the deflection will increase further. This deflection will further increase due to reducing elastic modulus of steel at elevated temperatures. This additional deflection due to P- $\Delta$ effects and reduced elastic modulus is called the magnification effects of thermal bowing (Figure 2(b)). The load capacity of LSF wall stud is considerably affected by the lateral deflection as it leads to additional bending action on the stud. Therefore lateral deflection of studs must be calculated accurately by considering thermal bowing and its magnification effects. This section reviews the equations proposed by other researchers and compares their predictions of mid-height lateral deflections of studs with corresponding deflections from fire tests and FEA in references [9-12].

\subsection{Equations Proposed by Past Research}

Klippstein [1] proposed mid-height deflection versus time graphs for selected wall configurations based on test results (Figure 5). However, this figure cannot be used for other wall panel configurations.

Cooke [19] considered thermal bowing of simply supported steel members due to temperature gradient across the section and derived Equation 1 for mid-height deflection $\left(e_{\Delta T}\right)$,

$e_{\Delta T}=\frac{\alpha L^{2} \delta T}{8 b_{w}}$

where $\alpha$ is the thermal expansion coefficient for steel; $L$ and $b_{w}$ are the stud height and web depth, respectively, and $\delta T$ is the temperature difference across the depth of the member. This equation was later used by many researchers [2-7].

Gerlich et al. [2] included both the thermal bowing and its magnification effects. Therefore the total lateral deflection $(e)$ of the stud is the sum of the thermal deflection $\left(e_{\Delta T}\right)$ and the deflection due to P- $\Delta$ effects $\left(e_{P \Delta T}\right)$. The stress-free thermal bowing was treated as an initial eccentricity $e_{\Delta T}$, calculated using Equation 1 . The initial bending moment $P^{*} e_{\Delta T}$ results in a further deflection $e_{P \Delta T}$ (magnification effects). This P- $\Delta$ component was predicted analytically by solving the moment equilibrium equation as 
$e_{P \Delta T}=e_{\Delta T}\left[\frac{1}{\cos \frac{\mu L}{2}}-1\right]$

where $\mu$ is $\sqrt{\frac{N^{*}}{E_{T} I_{X}}} ; E_{T}$ is the elastic modulus of steel at elevated temperature; $L$ and $I_{X}$ are the stud height and the second moment of area of the cross-section, respectively, and $N^{*}$ is the applied axial load.

Ranby [3] considered the net lateral deflection $\left(e_{\Delta T}-e_{\Delta E}\right)$ caused by the effects of both thermal bowing and neutral axis shift, and also their magnification effects, where $e_{\Delta \mathrm{T}}$ is the thermal bowing deflection and $e_{\Delta E}$ is the neutral axis shift due to changes in elastic modulus caused by non-uniform temperature distributions (Figure 6). This effective eccentricity causes an additional bending moment. This leads to more deflection and therefore an increase in the bending moment, and so on. This problem was solved iteratively until the value of $e$ in Equation 3(a) remains constant.

$$
e=\left(e_{\Delta T}-e_{\Delta E}\right) \frac{1}{1-\frac{N_{E d}}{N_{c r}}}
$$

where $N_{E d}$ is the applied axial load; $N_{c r}$ is the critical Euler buckling load about the major axis given by

$$
N_{c r}=\frac{\pi^{2} \sum E I_{g r}}{L^{2}}
$$

where $\Sigma E I g r$ is the sum of the bending stiffness weighted with the variation of the modulus of elasticity across the section.

$e_{\Delta E}$ is given by,

$$
e_{\Delta E}=\frac{b_{w}}{2}-\frac{\left(b_{f}+b_{l}\right) \frac{t}{2} E_{c f}+b_{w} \frac{b_{w}}{2} E_{w}+\left(b_{f}+b_{l}\right)\left(b_{w}-\frac{t}{2}\right) E_{h f}}{\left(b_{f}+b_{l}\right)\left(E_{c f}+E_{h f}\right)+b_{w} E_{w}}
$$

where $b_{w}, b_{f}$ and $b_{l}$ are the element widths of web, flange and lip; $t$ is the thickness; $E_{c f}, E_{w}$ and $E_{h f}$ are the elastic modulus of cold flange, web and hot flange. 
Feng and Wang [6] found the lateral deflection of LSF wall studs subjected to non-uniform temperature distributions using an energy method. The maximum lateral deflection of stud at mid-height is given by,

$e=e_{\Delta T}+e_{P \Delta T}-e_{\Delta E}$

where $e_{P \Delta T}$ is calculated as

$e_{P \Delta T}=\frac{\frac{2 \alpha \Delta T}{3 b_{w}} N_{E d} L}{\frac{64}{L^{3}} E I-\frac{16}{3 L} N_{E d}}$

where $N_{E d}$ is the applied load; $L$ and $b_{w}$ are the stud length and web depth, respectively; $E$ and $I$ are the weighted average elastic modulus and second moment of area of the cross-section based on the non-uniform temperature distribution, respectively. EI can be calculated using $E I=\sum_{i=1}^{q} E_{i}\left[I_{i}+A_{i} x_{i}^{2}\right]$ where the cross-section is divided into $q$ parts, and for each part $E_{i}$ is the reduced elastic modulus at temperature $T_{i}$.

Zhao et al. [7] proposed Equation 5 to calculate the mid-height lateral deflection e.

$e=\left(e_{L}-e_{\Delta E}+e_{\Delta T}+e_{P \Delta T}\right)$

with $e_{\Delta E}=\frac{\sum_{i} E_{i, \theta} y_{i} A_{i}}{\sum_{i} E_{i, \theta} A_{i}}$ and $e_{\Delta T}+e_{P \Delta T}=e_{\Delta T} \frac{1}{1-\frac{N_{E d}}{N_{c r}}}$

where $e_{L}$ is the initial eccentricity of the applied load and other parameters have been defined in this section.

\subsection{Comparison of Lateral Deflections from Fire Tests, FEA and Proposed Equations}

Figures 7 (a) to (c) compare the lateral deflections obtained from experiments, FEA and equations proposed by other researchers $[2,3,6,19]$. Finite element analyses under transient conditions were not performed for the tests conducted in [9]. Therefore comparisons in Figures 7 (d) to (j) are only with test results. Measured temperatures of hot and cold flanges obtained from tests were used in the predictions of lateral deflections using FEA and equations. The measured deflections in fire tests and FEA only include the thermal bowing and its magnification effects. Therefore the neutral axis shift was not considered in these figures for comparison purposes with FEA and experiments. Hence although Ranby [3] and 
Zhao et al. [7] proposed slightly different methods in predicting the effective eccentricity required for load capacity calculations, they were identical when neutral axis shift was ignored. Therefore only Ranby’s [3] method was plotted in Figure 7.

Cooke's [19] equation only predicts the lateral deflection due to thermal bowing and hence the predictions are smaller than those from FEA and previous research that included magnification effects. The lateral deflections obtained from FEA and proposed equations followed the same trend although there are some differences between them and the test values during the early stages of the test.

\section{Fire Design Rules based on AISI Design Manual}

In this section the fire design rules proposed by other researchers [1,2] to predict the load capacity of LSF wall studs subject to non-uniform elevated temperature distributions are reviewed and their predictions are compared with our results from FEA and fire tests [9-12]. The axial compression capacity of a LSF wall stud was calculated using these design rules at closer time intervals during each of the standard fire tests reported in Table 1 based on the measured time-temperature profiles of studs. These capacities were then plotted as load ratio versus time curves for each test where the load ratio is defined as the ratio of stud capacities at non-uniform elevated temperatures and ambient temperature. Sample design capacity calculations are given in [10].

\subsection{Klippstein’s [1] Design Rules}

Klippstein's fire design model is based on the allowable stress method given in AISI [20]. The ability of the gypsum boards to carry any vertical loads was neglected by all the researchers [1-7]. However, it was assumed that the failure by weak axis flexural buckling or torsional buckling is prevented by the plasterboards. The failure load $N^{*}$ of stud at elevated temperatures $(T)$ was calculated using,

$$
N^{*}=\frac{1}{A\left(\frac{23}{12} f_{a l T}\right)}+\frac{e}{S_{x} f_{y T}}
$$

where $A$ and $S_{x}$ are the gross area and the major axis section modulus, respectively; $e$ is the total mid-height lateral deflection of the stud; $f_{y T}$ is the yield strength at elevated temperatures and falt is the allowable axial stress at elevated temperatures calculated using Equation 6(b). 


$$
f_{a l T}=\frac{12}{23} Q_{T} f_{y T}-\frac{3}{23} \frac{\left(Q_{T} f_{y T}\right)^{2}}{\pi^{2} E_{T}}\left(\frac{k L}{r}\right)^{2}
$$

where $Q_{T}$ is the ratio between the effective area at elevated temperatures and the gross area; $f_{y T}$ and $\mathrm{E}_{\mathrm{T}}$ are the yield strength and the modulus of elasticity at elevated temperatures, respectively; $k L$ is the effective length and $r$ is the radius of gyration about the major axis.

Although the average temperature of the stud was used in [1] to find $f_{y T}$ and $E_{T}$; the weighted average $f_{y T}$ and $E_{T}$ were used here for consistency.

\subsection{Gerlich et al.'s [2] Design Rules}

Gerlich et al. [2] neglected torsional-flexural buckling and found that the failure mode of studs in LSF wall systems under fire was governed by the buckling of the compression flange on the ambient side. The stud failure was checked only for the mid-height cold flange of the studs based on [20] using,

$\frac{N^{*}}{P_{n}}+\frac{M^{*}}{M_{n x}}=1$

where $N^{*}$ is the applied axial compression load; $M^{*}=N^{*} e$ where $e$ is as given by Equation 2; $P_{n}=A_{\text {eff }} * f_{n}$ where $A_{\text {eff }}$ is the effective area at ambient temperature and $f_{n}$ is the critical stress using the yield stress at cold flange temperature and elasticity modulus at average stud temperature; $M_{n x}=f_{y T} * S_{x}$ where $f_{y T}$ is the yield stress at cold flange temperature and $S_{x}$ is the major axis gross section modulus at ambient temperature.

The LSF wall stud capacity can be calculated ( $N^{*}$ from Equation 7 ) based on the measured temperatures of hot flange, web and cold flange at a given time during each test. An iterative process is used to include the magnification effects in Equation 2.

\subsection{Discussion}

Figures 8 (a) to (j) compare the variation of load ratio with time from FEA and fire design rules proposed by [1,2]. Figure 5 does not apply to the wall configurations considered here. Hence the measured experimental lateral deflection values were used for the calculations based on [1]. During the early stages of the test the measured lateral deflection was high compared to the predicted deflection as discussed in Section 4.2 and thus the ultimate compression capacities of LSF wall studs based on [1] were lower than FEA results (Figure 
8). During the final stages of many tests, the lateral deflection reversed its direction and hence Klippstein’s [1] design rule resulted in arbitrary values.

Gerlich et al. [2] compared the critical temperature found by the model with the compression flange temperature on the ambient side of the wall to determine the failure time. Therefore their calculations of critical stress and bending moment capacity were based on the yield stress at cold flange temperature. However, the average temperature was used in the calculation of elastic modulus. This resulted in the over-estimation of failure times of LSF wall panels using their design rules. For cavity insulated wall panels the cold flange temperature is much lower than the hot flange temperature. Therefore the predicted failure times in these cases using [2] were much higher than those from FEA (Figure 8 (f) to (h)).

Effect of local buckling is considered in [1,2] by using the effective area of studs. Gerlich et al. [2] always used the effective area at ambient temperature based on the critical stress $f_{n}$ and effective element widths using ambient temperature properties (constant Q). However, Klippstein [1] used a form factor $Q_{T}$ at elevated temperature and calculated it using the critical stress $f_{n}$ and effective widths at elevated temperatures. Detailed calculations based on [17] to determine the effective areas of studs at ambient and elevated temperatures are given in [10]. Stud 3 of Test 1 (Hot and cold flange temperatures of $656^{\circ} \mathrm{C}$ and $492^{\circ} \mathrm{C}$ ) was used in these calculations and the effective areas were 167 and $176 \mathrm{~mm}^{2}$.at ambient and elevated temperatures, respectively.

Both Klippstein [1] and Gerlich et al. [2] used the gross section to calculate the moment capacity. However, the effective section should have been used to find the section modulus as was done by others [3-7]. They considered thermal bowing and its magnification effects, but not the neutral axis shift.

\section{Fire Design Rules based on Eurocode 3}

Previous researchers [3-7] considered that that the basic design equations given in Eurocode 3 Part 1.3 [15] for members under combined axial compression and bending subject to flexural and flexural-torsional buckling at ambient temperature could be used to find the ultimate capacity of LSF wall studs subject to combined axial compression and bending actions under non-uniform elevated temperature distributions. In all the previous studies except [6], the 
minor axis bending was not considered due to the available plasterboard restraint. Feng and Wang [6] included the neutral axis shift about the minor axis and corresponding bending moment. However, they then concluded that this effect is negligible and can be ignored in the fire design of LSF wall studs. Therefore the relevant equation in [15] for the combined actions of bending and compression can be reduced to

$$
\frac{N_{E d}}{\chi_{x} f_{y} A_{e f f} / \gamma_{M 1}}+\frac{k_{x x}\left(M_{x, E d}+\Delta M_{x, E d}\right)}{\chi_{L T} f_{y} W_{e f f, x} / \gamma_{M 1}}=1
$$

where $N_{E d}$ is the applied axial load according to [15]; $f_{y}$ is the basic yield strength; $A_{\text {eff }}$ is the effective cross-sectional area subject to compression; $\gamma_{M 1}$ is the partial factor for resistance of members to instability; $M_{x, E d}$ is the applied bending moment about the major axis; $\Delta M_{x, E d}$ is the additional moment; $W_{\text {eff, } x}$ is the effective section modulus for the maximum compressive stress in an effective cross-section subject to moment about the major axis; $\chi_{x}$ is the reduction factor due to flexural buckling; $\chi_{L T}$ is the reduction factor due to lateral torsional buckling, and $k_{x x}$ is the interaction factor given by,

$$
k_{x}=1-\frac{\mu_{x} N_{E d}}{\chi_{x} f_{y} A_{e f f}}
$$

with $\mu_{x}=\bar{\lambda}\left(2 \beta_{M, x}-4\right)$ where $\bar{\lambda}$ is the non-dimensional slenderness and $\beta_{M, x}=1.3$

The bending moment about the major axis is developed due to three separate effects caused by non-uniform temperature distribution in LSF wall studs. They are the thermal bowing, magnification effects and the neutral axis shift as explained in Section 4. If the effective eccentricity due to these three effects is denoted as " $e$ " then the bending moment about the major axis is $N_{E d} e$. For members not susceptible to torsional deformations, $\chi_{L T}$ is equal to 1.0. Hence with the assumption of $\gamma_{M 1}$ equal to 1, Equation 8(a) is reduced to

$$
\frac{N_{E d}}{\chi_{x} f_{y} A_{e f f}}+\frac{k_{x x} N_{E d} e}{f_{y} W_{e f f, x}}=1
$$

In Equation 9, the component $f_{y} A_{\text {eff }}$ is the ultimate failure load for local buckling $N_{\text {eff }}$ and the component $f_{y} W_{e f f, x}$ is the section moment capacity $M_{x, \text { eff }}$ of LSF wall stud. Hence the common equation used by all the previous research [3-7] is 


$$
\frac{N_{E d}}{\chi_{x} N_{\text {eff }}}+\frac{k_{x x} N_{E d} e}{M_{x, \text { eff }}}=1
$$

To find the ultimate load $N_{E d}$ of LSF wall stud at non-uniform elevated temperatures, the parameters $k_{x x}, e, \chi_{x}, N_{\text {eff }}$ and $M_{x, \text { eff }}$ should be determined accurately by taking into account the effects of non-uniform temperature distribution in studs. However, various simplifications were used by previous researchers [3-7] in the calculation of these parameters and hence different ultimate loads were obtained for LSF wall studs at elevated temperatures. Following sections present the details of design rules as presented by these researchers [3-7].

\subsection{Ranby's [3] Design Rules}

Ranby [3] considered stud deflection only about the major axis and hence used Equation 9 with $W_{\text {eff, } x}$ determined based on failure on the cold-flange.

$\frac{N_{E d}}{\chi_{x} f_{y} A_{\text {eff }}}+\frac{k_{x x} N_{E d} e}{f_{y}\left(\frac{I_{e f f}}{\bar{y}_{C F}}\right)} \leq 1 \quad$ with $\beta_{M, x}=1.3$

Equation 11 is re-arranged as

$$
N_{E d}=\frac{\chi_{x} f_{y} A_{e f f}}{1+\frac{k_{x x} e \bar{y}_{C F} \chi_{x} A_{e f f}}{I_{e f f}}}
$$

where Aeff and Ieff are the effective area and effective second moment of area at ambient temperature, however, $e$ is calculated using Equation 3 and the varying elastic modulus values across the stud section for its non-uniform temperature distribution; $f_{y}$ is the yield stress at average stud temperature; $\bar{y}_{C F}$ is the distance from cold flange to the effective neutral axis.

\subsection{Wang and Davies' [4] Design Rules}

Wang and Davies [4] used the design equations in [15] with appropriate elevated temperature properties to calculate the fire resistance of steel members with non-uniform temperature distributions. The ambient temperature approach was found to be suitable for fire conditions by taking into account the reductions in the strength and stiffness of steel at elevated temperatures, and the additional bending moments due to thermal bowing and neutral axis shift. Feng and Wang [6] extended this study further, which will be discussed later in this paper. Hence Wang and Davies’s [4] method is not investigated here. 


\subsection{Kaitila's [5] Design Rules}

Kaitila [5] initially proposed a uniform elevated temperature method in which the maximum (hot flange) temperature of the stud cross section was used as the uniform temperature in all the calculations. This method was used here to determine whether such simplified calculations can be used to determine the capacity of LSF wall studs subjected to non-uniform elevated temperatures. Figure 9 shows the variation of load ratios with time in comparison with FEA results. At higher load ratios, this method did not predict the LSF wall stud capacities. However, at lower load ratios $(<0.4)$ when the stud withstands higher temperatures the effect of non-uniform temperature distribution is negligible. Hence the uniform temperature method agrees reasonably well for all the tests with lower load ratios. Kaitila [5] used the effective area at ambient temperature in the fire design rules. In our study Kaitila's uniform temperature method was further investigated by using the effective area at elevated uniform temperatures (Figure 9). This improved the level of agreement, but is still not acceptable for higher load ratios.

Kaitila [5] then proposed an improved method for LSF wall studs subjected to non-uniform temperature distributions using Ranby's [3] method. The only change is the calculation of section modulus $W_{\text {eff, } x}$ which was based on the flange that is furthest away from the effective centroid, ie. $I_{\text {eff }} /\left(d-\bar{y}_{C F}\right)$ as Ranby's [3] equation overestimated the capacity when $I_{\text {eff }} /\left(\bar{y}_{C F}\right)$ was used. Hence the new equation proposed in [5] for the non-uniform temperature case is

$$
N_{E d}=\frac{\chi_{x} f_{y} A_{e f f}}{1+\frac{k_{x x} e\left(d-\bar{y}_{C F}\right) \chi_{x} A_{e f f}}{I_{e f f}}}
$$

where $d$ is the web height and all other parameters are as defined in Equations 8(a) and 12.

Figures 10 (a) to (j) show the variation of load ratios with time from FEA and the proposed design rules in [3,5]. Ranby's [3] equation and the modified equation proposed in [5] for nonuniform temperature case agreed well with FEA results. They agreed well with each other for non-insulated and externally insulated wall panels (Figures 10 (a) to (e) and 10 (i) and (j)). 
However, Ranby's [3] method overestimated the stud capacity (Figures 10 (f) to (h)) for cavity insulated wall panels. This is because when the temperature difference is high between the hot and cold flanges, the difference between $\left(\bar{y}_{C F}\right)$ and $\left(d-\bar{y}_{C F}\right)$ is also high in Equations 12 and 13.

\subsection{Feng and Wang's [6] Design Rules}

In the study of Feng and Wang [6], the stud cross-sections at both mid-height and support were checked using Equation 10. At mid-height $e$ includes thermal bowing, magnification effects and neutral axis shift based on Equations 4(a) and 4(b) while at the support it only includes the neutral axis shift. Neutral axis shift calculations included the effects of varying elasticity modulus on the effective section in compression. In the calculation of $e, E I$ (Equation 4(b)) was calculated based on the gross section with elasticity modulus values at elevated temperatures, and an iterative process was used to determine the stud capacity. $N_{\text {eff }}$ was calculated at elevated temperatures as $N_{\text {eff }}=A_{e f f} f_{y T}$ where $f_{y T}$ is the weighted average yield stress of the cross-section using the non-uniform temperature distribution; Parameters $A_{\text {eff }}, \chi_{x}$ and $M_{x, \text { eff }}$ are defined in the following sections.

\subsubsection{Calculation of Effective Area $A_{\text {eff }}$}

Two methods were investigated in [6] to find the ultimate capacity of LSF wall studs at nonuniform elevated temperatures. Therefore in their first method Feng and Wang [6] used Equation 10 with effective area calculated at ambient temperature. In addition, they allowed for temperature effects on the effective cross-section of stud as shown in Figure 11 in their second method based on [15]. A uniform temperature distribution was assumed for flanges and lips and their effective widths were calculated using elevated temperature properties. The weighted average elastic modulus was used to calculate the effective width of web. The sum of the product of calculated effective width of each element, its thickness and the yield stress at its temperature was used as $N_{\text {eff }}$.

Detailed calculations of the effective areas under concentric compression at ambient and elevated temperatures based on [15] are shown in [10]. Stud 3 in Test 1 with the failure hot and cold flange temperatures of $656^{\circ} \mathrm{C}$ and $492^{\circ} \mathrm{C}$ was used in these calculations, and its effective areas were 131 and $164 \mathrm{~mm}^{2}$. 


\subsubsection{Calculation of Flexural Buckling Reduction Factor $\chi_{x}$}

In the first method this factor was calculated using the relevant fire design rules in [14] using ambient temperature properties and a modification factor $\overline{\lambda_{\theta}}$ to allow for elevated temperature effects. For the second method, ambient temperature design rules in [15] were used with weighted average mechanical properties and effective area at elevated temperatures.

\subsubsection{Calculation of Section Moment Capacity $M_{x, e f f}$}

The section moment capacities about the major axis were calculated separately for stud midheight and support in [6]. At mid-height, the stud is bent towards the hot side (due to thermal bowing) and hence the hot flange will be subject to tensile stresses due to bending. At this time, the yield stresses of the hot side will be very low compared to cold side. Therefore, for mid-height calculations, section moment capacity was found by considering that the tension stresses at the extreme fibres (hot flange and some parts of web) have reached yield (partial plasticity) and the maximum compression stress at the extreme fibre (cold flange) is equal to the yield stress (first occurrence of material yield). For support calculations, the stud is bent towards the cold side (due to neutral axis shift) and the hot flange is under compression and has lower yield strength. Therefore the first occurrence of material yield on the compression (hot) side was considered. This time the partial plasticity of the cold side is not possible since the cold side will have higher yield capacity. Further details are given in Section 6.6.4.

\subsection{Zhao et al.’s [7] Design Rules}

Zhao et al [7] used Feng and Wang's [6] second method based on Eurocode 3 Part 1.3 [15] design rules, but with some modifications. The load capacity of studs in compression, $N_{E d}$, was expressed as follows by including a new parameter, $\bar{\lambda}_{\theta}$, the relative slenderness at elevated temperature.

$N_{E d}=\chi_{x}\left(\overline{\lambda_{\theta}}\right) N_{e f f}$

where $N_{\text {eff }}$ was calculated according to Section 6.4; $\chi_{x}$ is defined in Equation 8(a) and

$\overline{\lambda_{\theta}}=\sqrt{\sum_{i} A_{i} f_{y, \theta, i} / N_{f i, c r}}$ with $N_{f i, c r}=\pi^{2}(E I)_{f i} / L_{\theta}^{2}$ and $(E I)_{f i}=\sum_{i} E_{i, \theta} I_{i, \theta}$

where $A_{i}$ is the initial element area; $f_{y, \theta, i}$ is the $0.2 \%$ proof yield strength of steel at temperature $\theta_{i} ; N_{f i, c r}$ is the Euler buckling load and $L_{\theta}$ is the buckling length of stud in fire situation; $(E I)_{f i}$ is the gross flexural stiffness of the cross-section; $E_{i, \theta}$ is the modulus of elasticity of each plate element; $I_{i, \theta}$. is the second moment of area of each element and $\theta$ is the elevated temperature. 
Zhao et al. [7] considered only the bending action about the major axis and hence Equation 10 was used. They took $k_{x x}$ as 1.0 and $e$ was calculated as $e=\left(e_{L}-e_{\Delta E}\right)$ at the support and $e=\left(e_{L}-e_{\Delta E}+e_{\Delta T}\right)$ at the mid-height, where $e_{L}, e_{\Delta E}$ and $e_{\Delta T}$ are defined in Section 4.1.

The method in [15] was used to calculate their effective widths, but using the elevated temperature properties. The weighted average steel strength and stiffness values were used to calculate the web effective width. However, in our study the mechanical properties at web mid-height were used to determine the effective width of web for comparison purposes.

Sample calculations of ultimate capacities of LSF wall studs based on [6,7] are given in [10]. Figures 12 (a) to (j) show the variation of load ratio with time based on the fire design methods of [6,7]. Feng and Wang's [6] second method based on [15] agreed well with the FEA results compared to Zhao et al. [7] and Feng and Wang's [6] method based on [14].

\subsection{Discussion of Previous Fire Design Rules based on Eurocode 3}

\subsubsection{Variation of Ultimate Load $N_{E d}$}

Figure 13 shows the variation of the ultimate load capacity of LSF wall stud with respect to time from previous studies. Average measured temperature values of Stud 3 in Test 1 were used for hot and cold flange temperatures. At ambient temperature $(t=0)$ Kaitila's [5] and Feng and Wang's [6] methods using [15] resulted in the same ultimate capacity of $52.2 \mathrm{kN}$. However, Feng and Wang's [6] method using [14] and Zhao et al.'s [7] method gave smaller capacities of $44.6 \mathrm{kN}$ and $44.0 \mathrm{kN}$, respectively. The difference between the two methods proposed in [6] is due to the reduction factor $\chi_{x}$ for flexural buckling resistance. In [7] another reduction factor $\overline{\lambda_{\theta}}$ was used in addition to $\chi_{x}$ given in [15]. This will be explained in Section 6.6.5.

Although the ultimate loads at ambient temperature were different using the design rules proposed in [5-7], they merged together near the failure time when the stud temperature was increased considerably. The influence of several parameters $\left(k_{x x}, e, \chi_{x}, N_{\text {eff }}\right.$ and $\left.M_{x, \text { eff }}\right)$ on the design of LSF wall studs is discussed in the following sections. 


\subsubsection{Variation of Effective Eccentricity $e$}

Figure 14 shows the variation of effective eccentricity used to find the applied bending moment $\left(N_{E d} . e\right)$ in LSF wall studs subjected to non-uniform elevated temperature conditions. Past research proposed different methods to calculate this eccentricity by including the effects of thermal bowing, magnification effects and neutral axis shift (Section 4). However, Figure 14 shows that there is not much difference among them. The difference between Figures 7 (a) and 14 is the omission of neutral axis shift. The lateral deflection from tests and FEA do not include the neutral axis shift and hence Figure 7(a) did not include it for comparison purposes. However, the neutral axis shift based on the effective area should be considered to accurately calculate the load capacity of studs. In the methods proposed by [5] and [6] using [14], effective area was calculated at ambient temperature and thus $e$ is almost the same when these methods are used (Figure 14). Similarly in the methods proposed in [6,7] using [15], effective area was calculated at elevated temperatures and thus e is almost the same here (Figure 14). The small variation between these methods is due to other differences in their calculation methods as discussed in Section 4.

\subsubsection{Variation of Ultimate Load for Local Buckling $N_{\text {eff }}$}

Figure 15(a) shows the variation of ultimate load for local buckling using the design rules proposed by other researchers while Figure 15(b) shows the effective area used by them to find these capacities. Kaitila [5] and Feng and Wang [6] used the effective area at ambient temperature to find the ultimate load for local buckling based on [14]. However, Feng and Wang [6] using [15] and Zhao et al. [7] used the effective area at elevated temperatures based on [15]. Therefore the effective area varied with time as shown in Figure 15(b). It was less than that at ambient temperature up to about 110 minutes (Figure 15(b)). Therefore the ultimate load for local buckling is also less according Feng and Wang [6] using [15] and Zhao et al. [7] as shown in Figure 15(a). Although the same effective area was used in [5,6] using [14], the ultimate load for local buckling is slightly different for each. This is due to the simplifications used in these fire design rules about the yield stress at elevated temperatures. Kaitila [5] used the yield stress at the average web temperature while a weighted average yield stress was used in [6]. Despite this, they agreed well in the prediction of ultimate load for local buckling. 


\subsubsection{Variation of Section Moment Capacity $M_{x, e f f}$}

Figure 16 (a) shows the variation of section moment capacity $M_{x, \text { eff }}$ with time using previous fire design rules. Kaitila [5] calculated the effective section modulus corresponding to the flange that is furthest away from the effective centroid. Therefore the $y_{\max }$ he used was the distance from effective neutral axis to the hot flange. However, Ranby [3] calculated the effective section modulus in relation to cold flange. In the studies of Feng and Wang [6] and Zhao et al. [7], partial plasticity was considered in the calculation of section moment capacity at mid-height.

Another difference between these fire design rules is the calculation method used to find $M_{x, \text { eff }}$ Kaitila [5] calculated the section moment capacity by simply multiplying the yield stress at average temperature by the effective section modulus. However, in [6,7] it was found by $\sum f_{i} A_{i} y_{i}$ where $f_{i}$ and $A_{i}$ are the developed stress and area, respectively, of the individual elements of the reduced (effective) cross-section. $y_{i}$ is the distance from the effective neutral axis to the force generated by $f_{i} A_{i}$ component of the individual elements in the reduced crosssection.

Figure 16(b) shows the variation of effective area used to calculate $M_{x, \text { eff. }}$ Kaitila [5] used the effective area for uniform compression at ambient temperature to find $M_{x, \text { eff }}$ at elevated temperature. Therefore large parts of web and tension flanges were unnecessarily lost in the calculation of $M_{x, \text { eff }}$ and thus resulted in the smallest $M_{x, \text { eff }}$ values. In Feng and Wang [6] using [14], the effective area calculated for pure bending at ambient temperature was used to calculate $M_{x, \text { eff }}$ at elevated temperatures. In the studies of [6,7] using [15], the effective area for pure bending was calculated at elevated temperatures. As shown in Figure 16(b), the effective area at ambient temperature was more than that at elevated temperatures for most of the time, resulting in higher $M_{x, \text { eff }}$ values for the method used by [6] based on [14].

\subsubsection{Variation of Reduction Factors Used in Fire Design}

Figure 17(a) shows the variation of reduction factor for flexural buckling resistance $\chi_{x}$ with time. The usage of an imperfection factor $\alpha$ to find $\chi_{x}$ is an important decision to make in Eurocode 3. The buckling curve b is suggested in [15] for channel sections that gives a value of 0.34 for imperfection factor $\alpha$. However, $\alpha$ is defined as $0.65 \sqrt{235 / f_{y}}$ in [14]. The yield 
stress of the steel considered in our research is $569 \mathrm{MPa}$. Hence an $\alpha$ value of 0.418 is used based on [14]. This resulted in lower $\chi_{x}$ values in the study of [6] using [14] (Figure 17(a)). Zhao et al. [7] used an additional reduction factor $\overline{\lambda_{\theta}}$ and hence their effective reduction factor is small compared to other researchers’ values as shown in Figure 17(a).

Figure 17(b) shows the variation of the modification factor $k_{x x}$ used in the previous fire design rules to take account of non-uniform bending moment distributions in the stud. In the studies of $[5,6]$ this factor was calculated using Equation 8(b) with elevated temperature properties. Even in the study of [6] using [14], they used the $k_{x x}$ factor given Equation 8(b). Eurocode 3 Part 1.3 [15] sets an upper limit of 1.5 for $k_{x x}$. When $k_{x x}$ was calculated based on Equation 8(b) for the measured temperature values of Test 1, it was always more than 1.5 and hence was limited to 1.5 (Figure 17(b)). In contrast, Zhao et al. [7] used a value of 1 for $k_{x x}$.

\section{Comparison of Previous Fire Design Rules}

Table 2 shows the effective areas used in the previous fire design rules. It shows the different effective areas used in finding the compression and section moment capacities. Table 3 shows the parameters and assumptions used with these fire design rules including thermal bowing, neutral axis shift and magnification effects.

\subsection{Failure Times Obtained from Previous Fire Design Rules}

Tables 4 to 6 show the failure times obtained from the previous fire design rules for the LSF wall systems in Table 1 under load ratios of 0.2, 0.4 and 0.7, respectively. Klippstein's [1] method resulted in arbitrary failure times compared to test and FEA results as discussed in Section 5.3. Gerlich et al.’s [2] fire design rules overestimated the failure times of LSF wall studs considerably due to the usage of cold flange temperature in the fire design.

Feng and Wang's [6] fire design rules agreed reasonably well with the test and FEA results. Among the two methods proposed by them, the fire design rules based on [15] agreed well with the test and FEA results. However, Feng and Wang's [6] and Zhao et al.'s [7] methods involve complex calculations and hence may not be suitable for routine designs. Ranby’s [3] method also slightly overestimated the failure times due to the assumption in finding the distance from the neutral axis to the extreme fibre. Kaitila [5] improved the fire design rules proposed in [3] by modifying the distance from the neutral axis to the extreme fibre. Hence 
Kaitila's [5] predicted failure times agreed well with test and FEA results. The uniform temperature method discussed in [5] can be used only when the load ratio is as low as 0.2.

\subsection{Modifications Recommended for Previous Fire Design Rules}

Klippstein's [1] study was based on the older AISI design manual and the measured deflection of LSF wall panels under fire conditions. Hence this method is not recommended for the fire design of LSF wall studs. Gerlich et al. [2] used the yield stress of cold flange to find the ultimate capacity of LSF wall studs. Hence a modification to use the weighted average yield stress at elevated stud temperature is recommended.

Ranby [3] and Kaitila [5] used the effective area at ambient temperature to find the ultimate capacity of LSF wall studs subject to non-uniform temperature conditions. However, this research has shown that effective area at elevated temperature should be used. In the determination of section moment capacity, they used the effective area for pure compression. This is not recommended and the effective area for bending must be used. In combining the effects of axial compression and bending, they have taken the effects of magnification effects twice in the form of $k_{x x}$ and Equation 3(a), which is not recommended.

Feng and Wang's [6] method was based on the older version of Eurocode 3 Part 1.3 [15]. However, it was revised in 2006 and the new design rules should be used. Their calculation methods based on [15] to find the section moment capacities at non-uniform temperatures are complicated. Hence a simplified method is desirable to reduce the complexity involved in the fire design of LSF wall studs. Zhao et al.'s [7] method is similar to Feng and Wang's [6] method and has the same shortcomings. In addition they used an additional reduction factor ( $\bar{\lambda}_{\theta}$ ) in calculating the ultimate compression capacity. The reason for this is not known and is not recommended.

\section{Conclusions}

This paper has presented the details of an investigation into the accuracy of available fire design rules in predicting the axial compression strength and failure times of LSF wall studs under standard fire conditions. The behaviour and strength of LSF wall studs subjected to non-uniform elevated temperature conditions during standard fires was analysed in detail. The mid-height lateral deflections of the studs due to non-uniform temperature conditions were 
predicted using the available equations proposed by previous research. It was found that these deflections agreed reasonably well with the lateral deflections obtained from finite element analyses. Applications of the previously developed fire design rules based on AISI design manual and Eurocode 3 to LSF wall studs were investigated in detail. The accuracy of these fire design rules was studied in comparison with the available test and FEA results and suitable modification were proposed where necessary.

\section{Acknowledgements}

The authors would like to thank Australian Research Council for their financial support and the Queensland University of Technology for providing the necessary facilities and support to conduct this research project.

\section{References}

[1] Klippstein, K.H. (1980), Strength of Cold-Formed Studs Exposed to Fire, American Iron and Steel Institute. Washington DC, USA.

[2] Gerlich, J.T., Collier, P.C.R. and Buchanan, A.H. (1996), Design of Steel-framed Walls for Fire Resistance, Fire and Materials, Vol.20, No.2, pp.79-96.

[3] Ranby, A. (1999), Structural Fire Design of Thin Walled Steel Sections, Licentiate Thesis, Department of Civil and Mining Engineering, Lulea University of Technology, Stockholm, Sweden.

[4] Wang, Y.C. and Davies, J.M. (2000), Design of Thin-walled Steel Channel Columns in Fire using Eurocode 3 Part 1.3, Proceedings of the First International Workshop on Structures in Fire, Copenhagen, pp.181-93.

[5] Kaitila, O. (2002), Finite Element Modelling of Cold-formed Steel Members at High Temperatures, Licentiate Thesis, Helsinki University of Technology Laboratory of Steel Structures, Espoo, Finland. 
[6] Feng, M. and Wang, Y.C. (2005), An Analysis of the Structural Behaviour of Axially Loaded Full-scale Cold-formed Thin-walled Steel Structural Panels Tested under Fire Conditions, Thin-Walled Structures, Vol.43, pp.291-332.

[7] Zhao, B., Kruppa, J., Renaud, C., O’Connor, M., Mecozzi, E., Apiazu,. W., Demarco, T., Karlstrom, P., Jumppanen, U., Kaitila, O., Oksanen, T. and Salmi, P. (2005), Calculation Rules of Lightweight Steel Sections in Fire Situations, Technical Steel Research, European Union.

[8] Alfawakhiri, F. (2001), Behaviour of Cold-formed-Steel-framed Walls and Floors in Standard Fire Resistance Tests, PhD Thesis. Department of Civil and Environmental Engineering, Carleton University, Ottawa, Canada.

[9] Kolarkar, P.N. (2010), Structural and Thermal Performance of Cold-formed Steel Stud Wall Systems under Fire Conditions, PhD Thesis, Queensland University of Technology, Brisbane, Australia.

[10] Gunalan, S. (2011), Structural Behaviour and Design of Cold-formed Steel Wall Systems under Fire Conditions, PhD Thesis, Queensland University of Technology, Brisbane, Australia.

[11] Gunalan, S., Kolarkar, P.N. and Mahendran, M. (2013), Experimental Study of Load Bearing Cold-formed Steel Wall Systems under Fire Conditions, Thin-Walled Structures, Vol. 64, pp.72-92.

[12] Gunalan, S. and Mahendran, M. (2013), Finite Element Modelling of Load Bearing Cold-formed Steel Wall Systems under Fire Conditions, Engineering Structures, Accepted.

[13] Dolamune Kankanamge, N. and Mahendran, M. (2011), Mechanical Properties of Coldformed Steels at Elevated Temperatures, Thin-Walled Structures, Vol.49, pp.26-44. 
[14] EN 1993-1-2 (2005), Eurocode 3: Design of steel structures. Part 1-2: General Rules Structural Fire Design, European Committee for Standardization, Brussels, Belgium.

[15] EN 1993-1-3 (2006), Eurocode 3: Design of Steel Structures. Part 1-3: General Rules Supplementary Rules for Cold-formed Members and Sheeting, European Committee for Standardization, Brussels, Belgium.

[16] EN 1993-1-5 (2006), Eurocode 3: Design of Steel Structures. Part 1-5: Plated Structural Elements, European Committee for Standardization, Brussels, Belgium.

[17] Standards Australia (SA) (2005), AS/NZS 4600 Cold-formed Steel Structures, Sydney, Australia.

[18] Feng, M., Wang, Y.C. and Davies, J.M. (2003), Axial Strength of Cold-formed Thinwalled Steel Channels under Non-uniform Temperatures in Fire, Fire Safety Journal, Vol.38, pp.679-707.

[19]Cooke, G.M.E. (1987), Thermal Bowing and how it affects the Design of Fire Separating Construction, Fire Research Station, Building Research Establishment, Herts, UK.

[20] American Iron and Steel Institute (AISI) (2007), Specifications for the Cold-formed Steel Structural Members, Cold-formed Steel Design Manual, Washington DC, USA. 


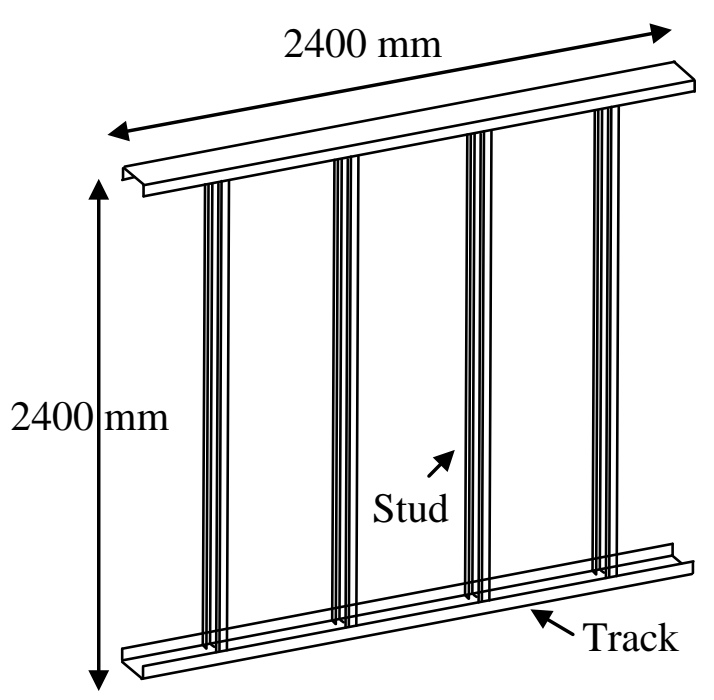

(a) Light gauge Steel Frame (LSF)

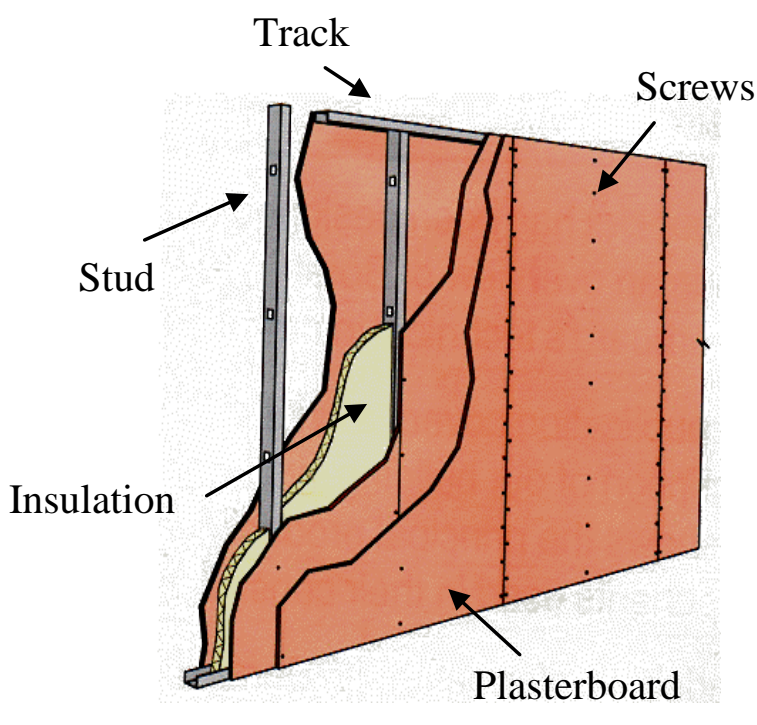

(b) LSF wall clad with plasterboards

Figure 1: LSF Wall System 


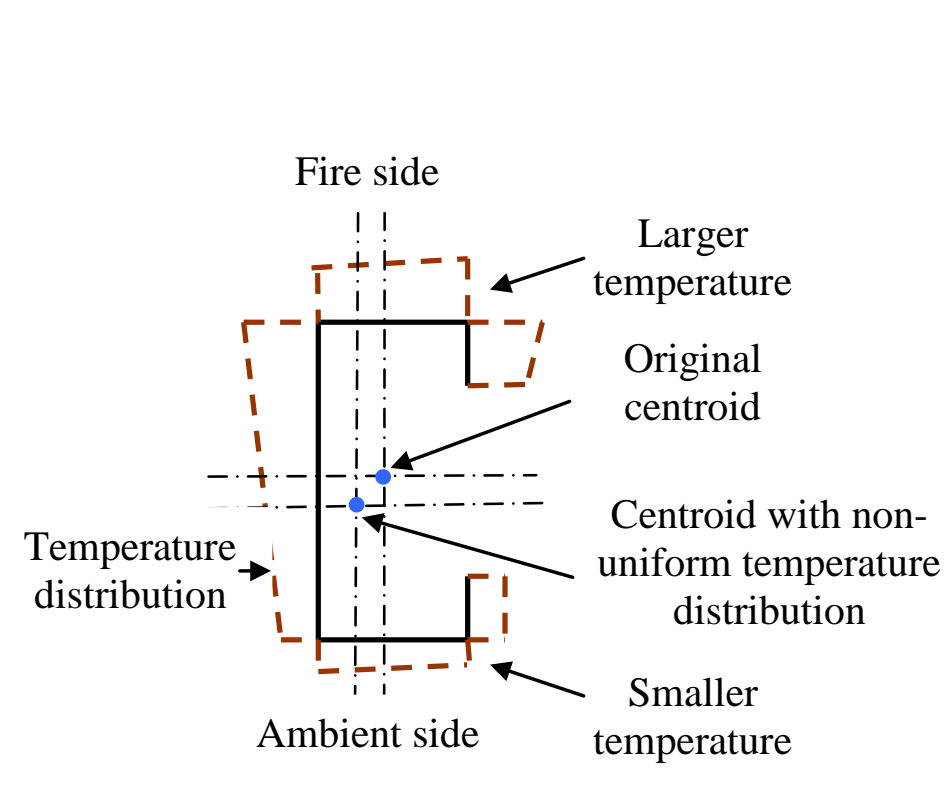

(a) Neutral axis shift $\left(e_{\Delta E}\right)$

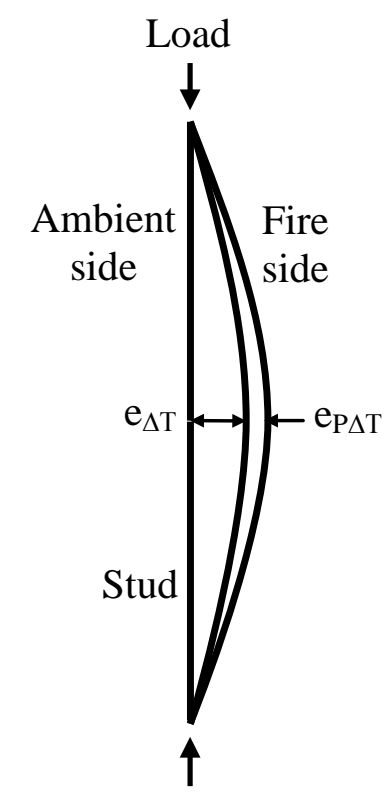

(b) Thermal bowing $\left(\mathrm{e}_{\Delta \mathrm{T}}\right)$ and magnification effects $\left(\mathrm{e}_{\mathrm{P} \Delta \mathrm{T}}\right)$

Figure 2: Behaviour of LSF Wall Studs when Subjected to Fire from One Side 


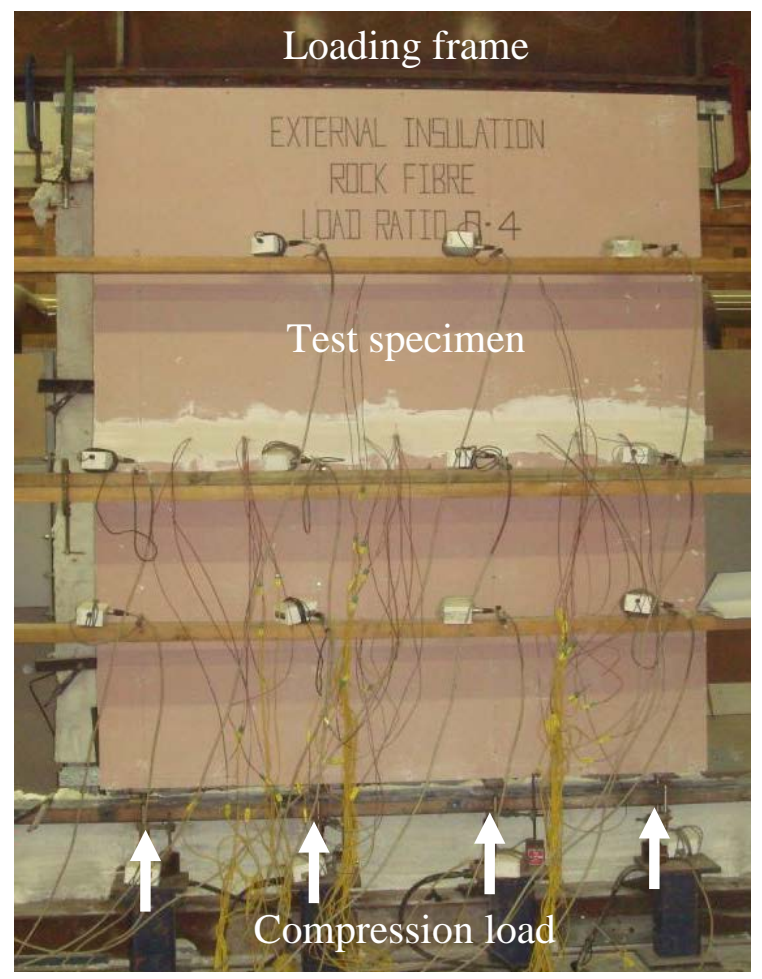

(a) Test Specimen before the test ambient side

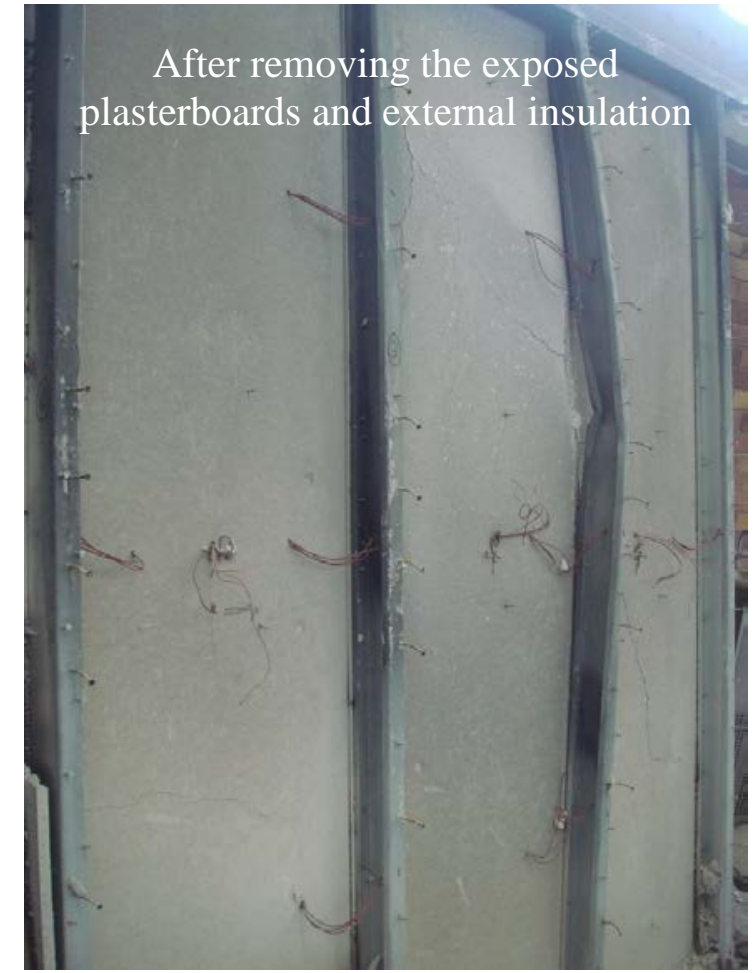

(b) Test Specimen after the test fire side

Figure 3: A Test Specimen Before and After a Test 


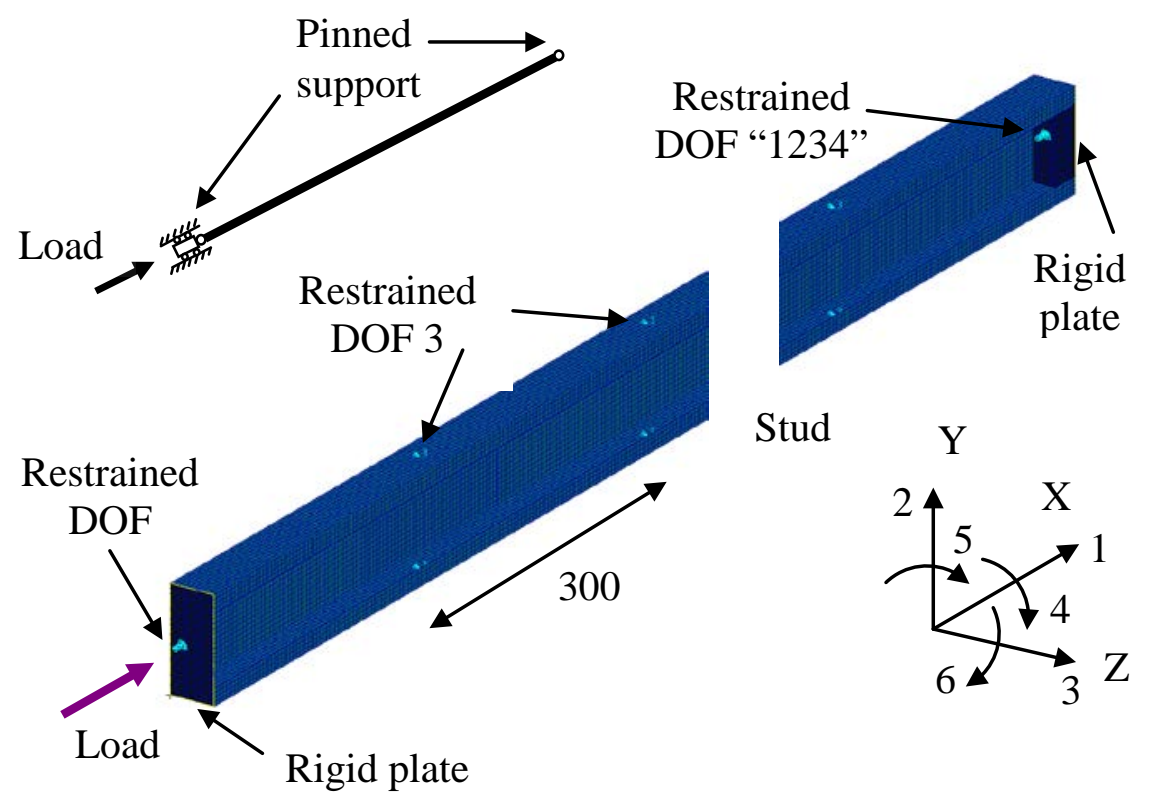

(a) Loading and boundary conditions

Patran 2008r1 01-Oct-10 14:04:59

Fringe: S3Temp, Step2,TotalTime=115.91_32, Deformation, Displacements, Magnitude, (NON-LAYERED) Deform: S3Temp, Step2,TotalTime=115.91_32, Deformation, Displacements,

Thermal expansion
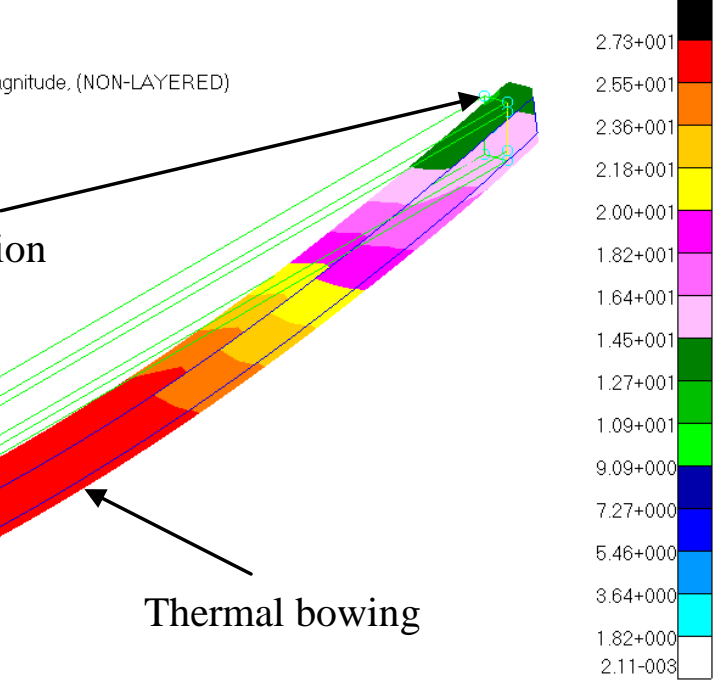

Fire side

Thermal bowing

default Fringe :

Max 2.73+001@Nd 31600

Min 2.11-003@Nd 33136

default_Deformation :

$\operatorname{Max} 2.73+001 @ N d 31600$

(b) Thermal bowing and expansion of the stud

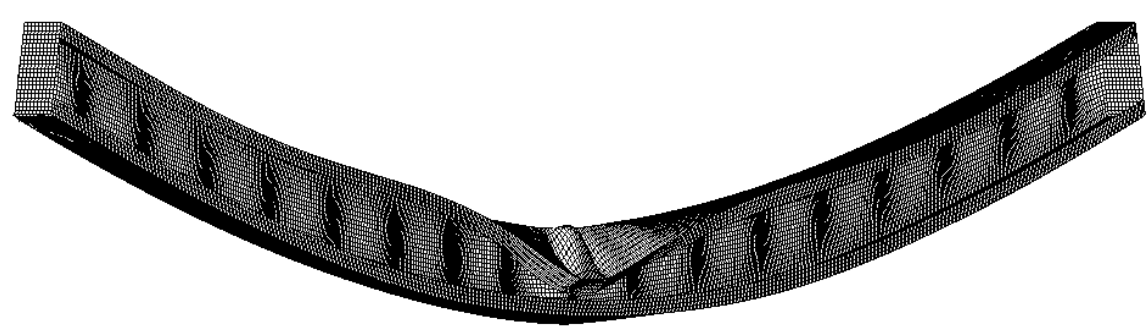

(c) Failure mode

Figure 4: Typical Predictions from a Numerical Study 


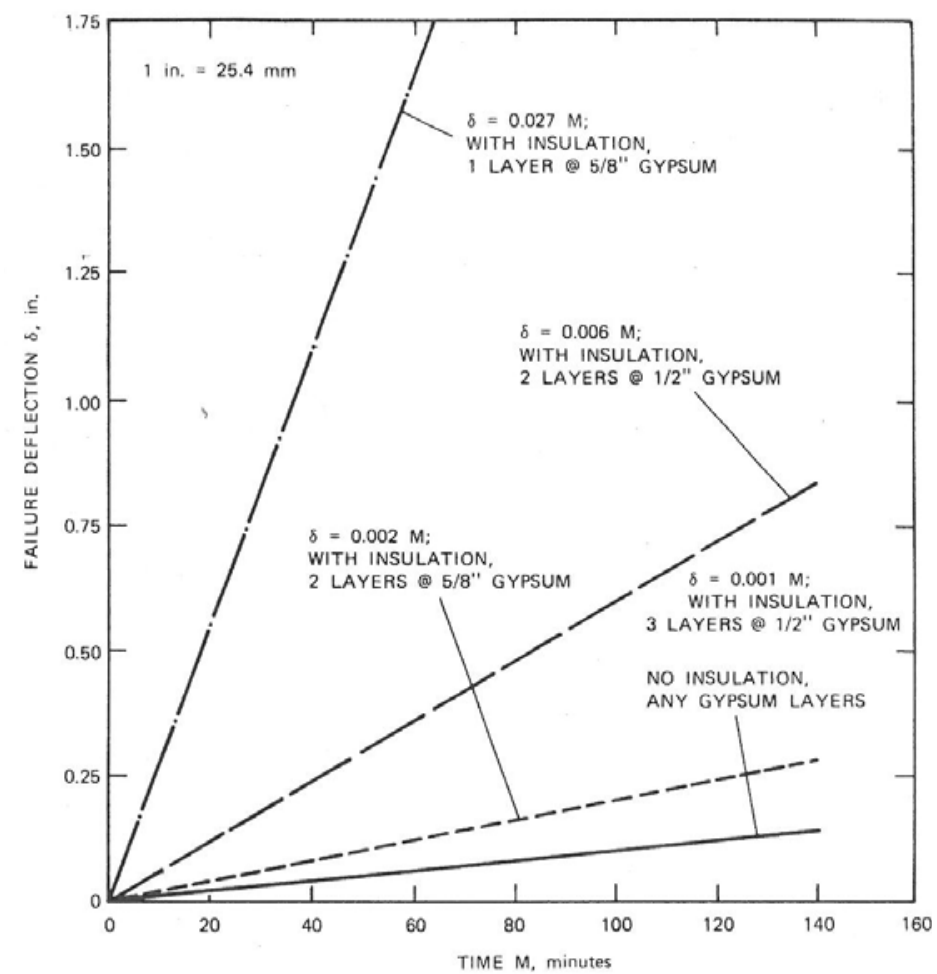

Figure 5: Estimated Failure Deflection of Studs in Wall Panels [1] 


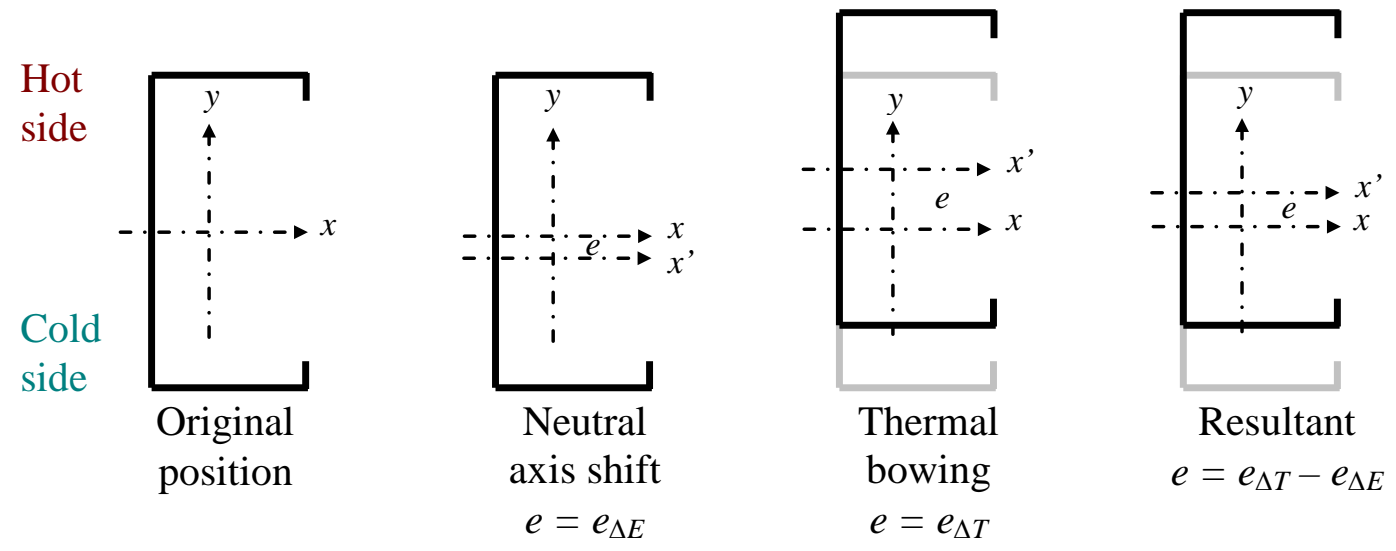

Figure 6: Lateral Deflections of LSF Wall Studs 


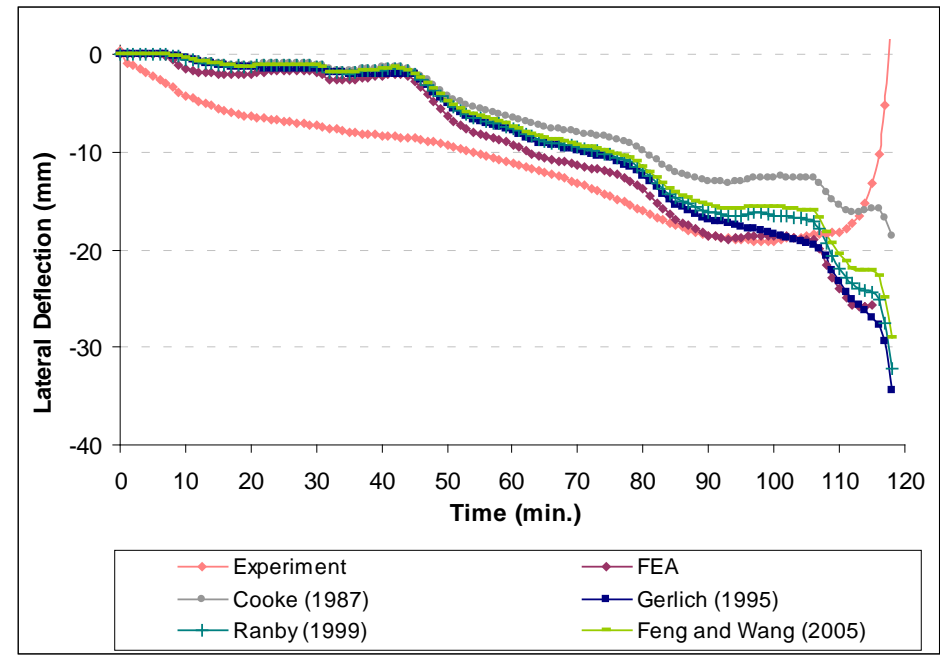

(a) Test 1

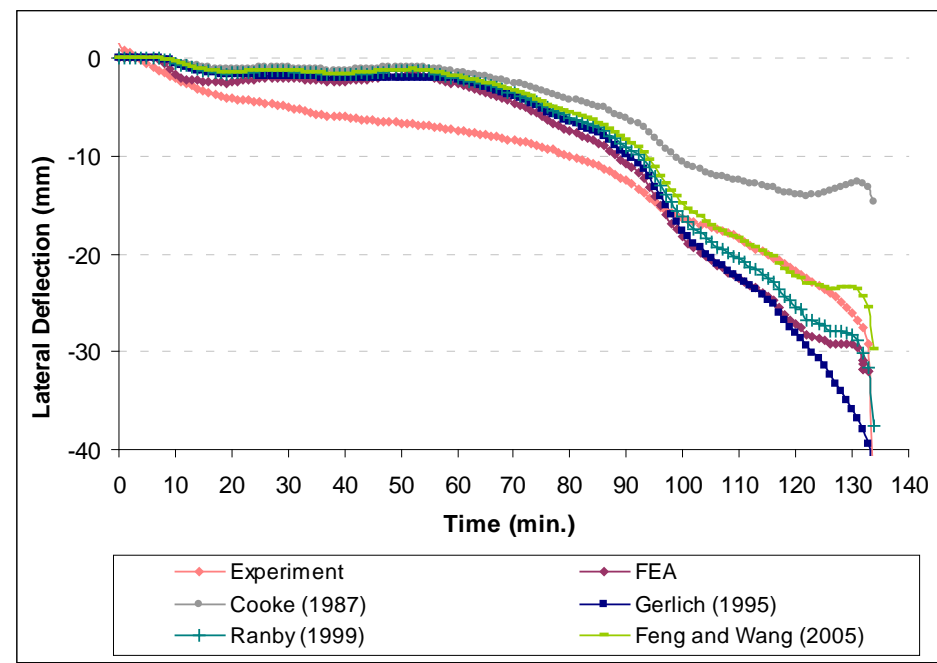

(c) Test 3

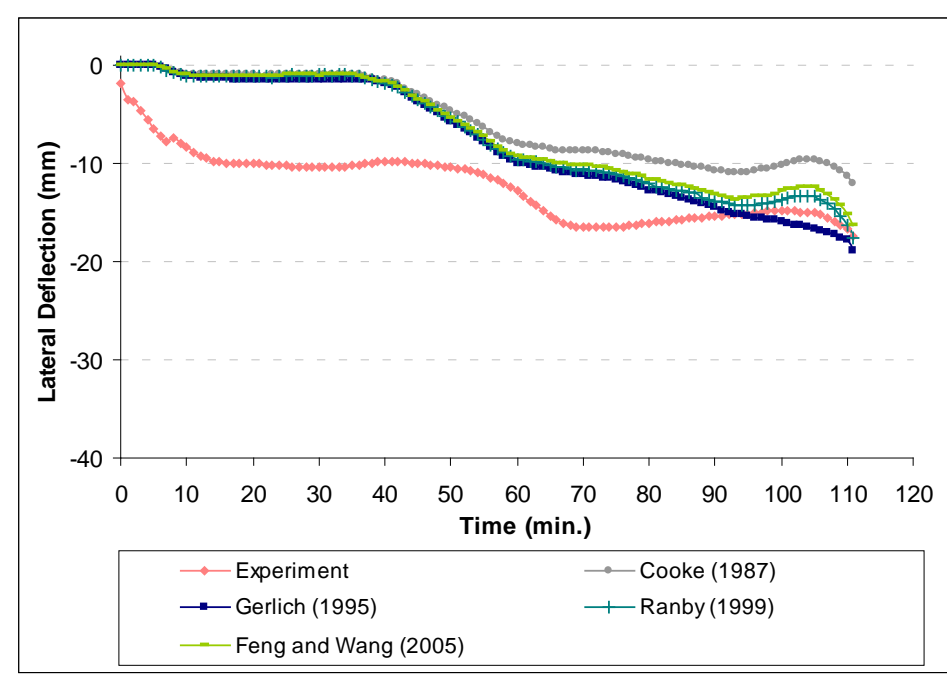

(e) Test 2*

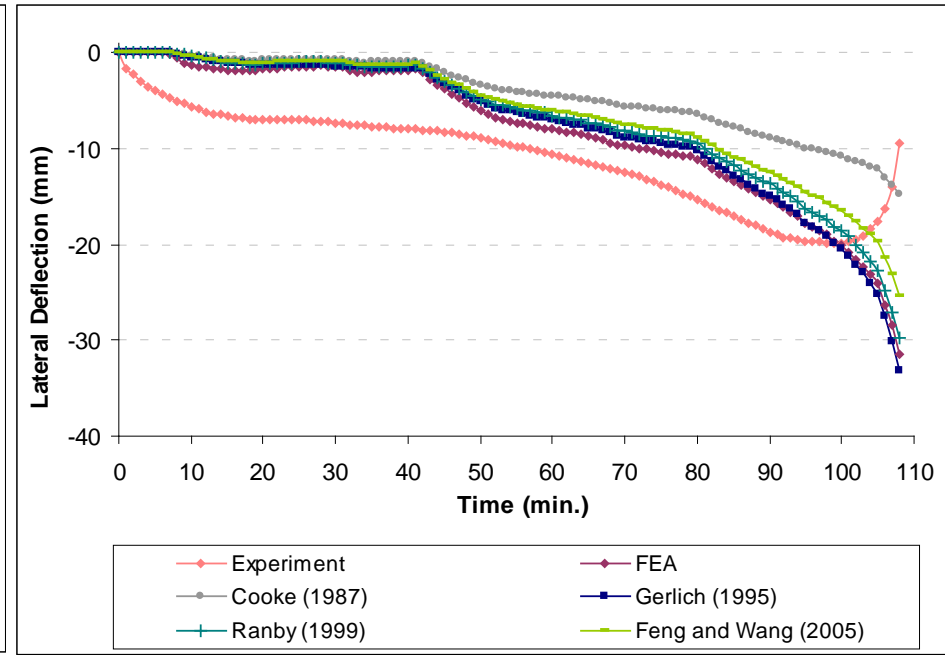

(b) Test 2

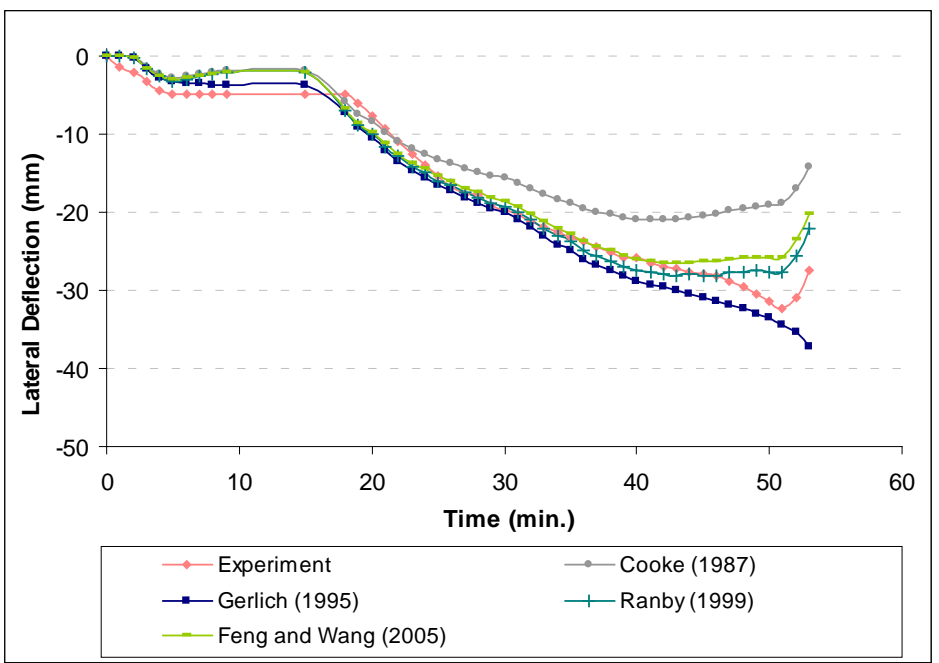

(d) Test $1 *$

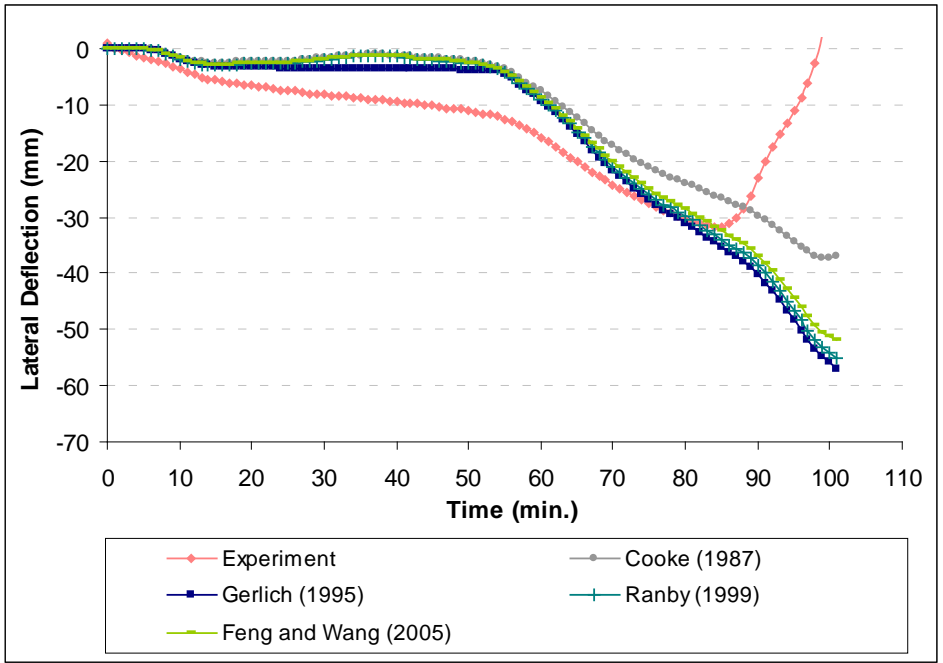

(f) Test 3*

Figure 7: Lateral Deflection versus Time Curves from Experiments and Previous Fire

\section{Design Rules}




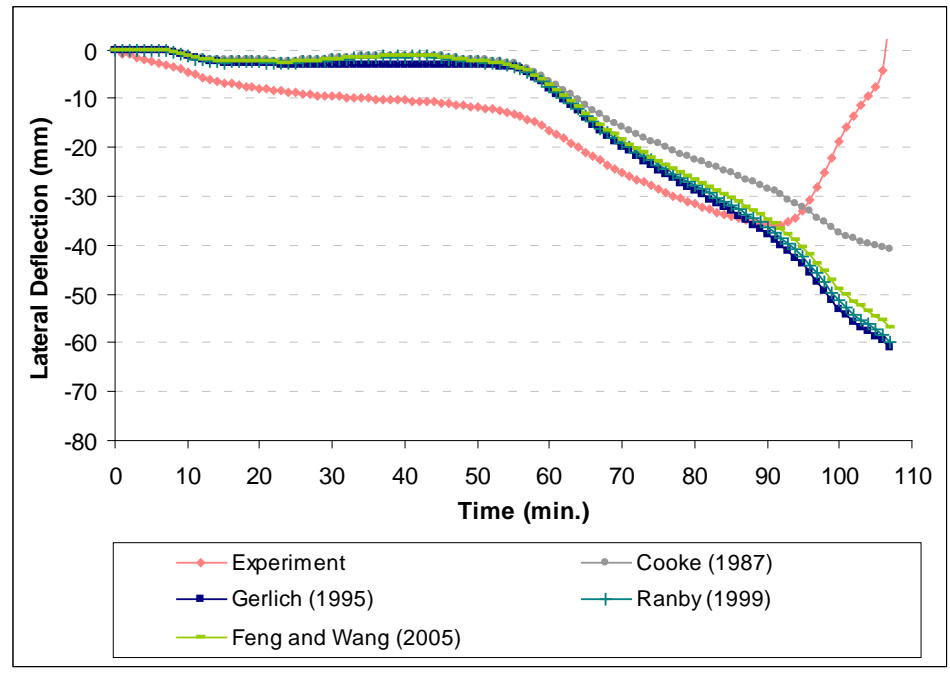

(g) Test $4 *$

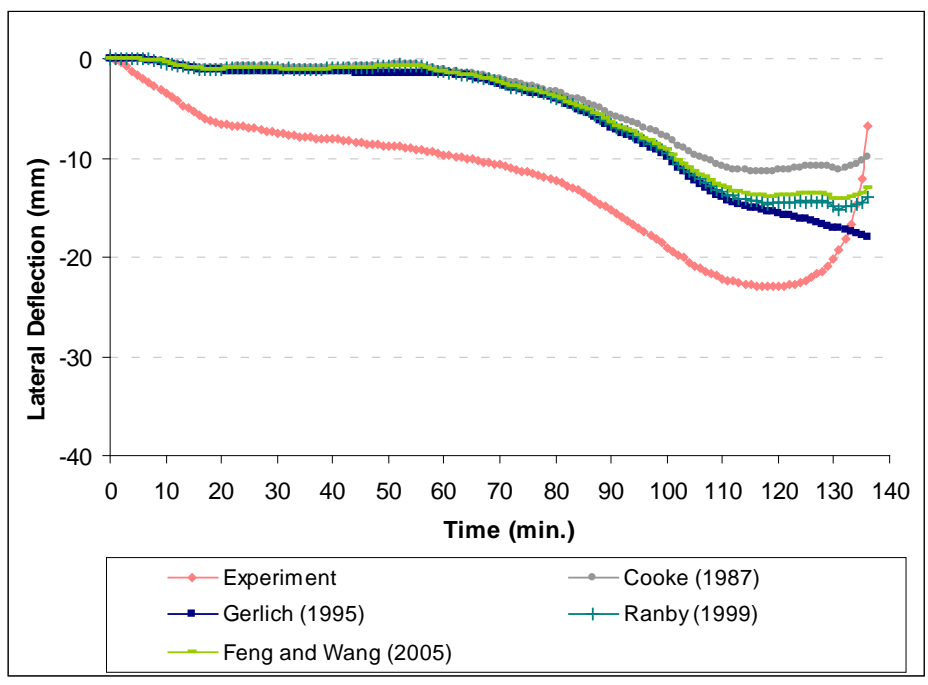

(i) Test 6*

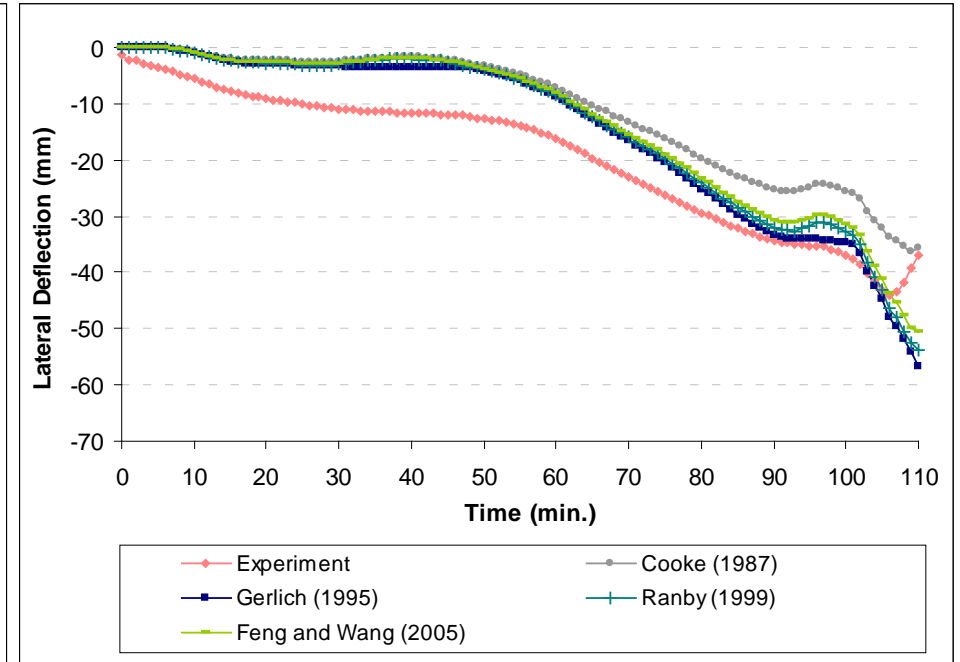

(h) Test 5*

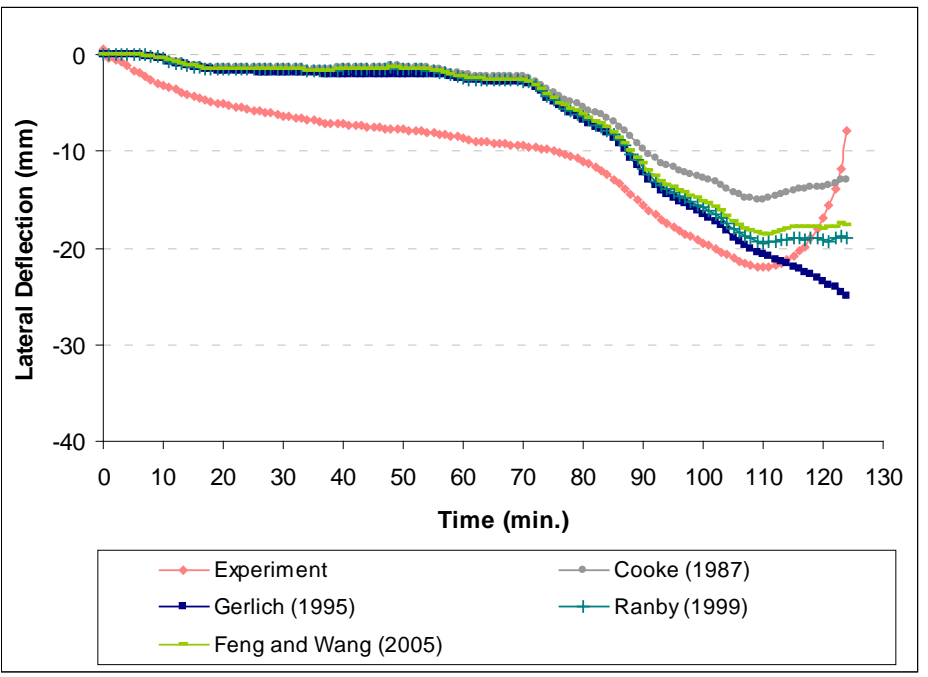

(j) Test 7*

Figure 7: Lateral Deflection versus Time Curves from Experiments and Previous Fire Design Rules 


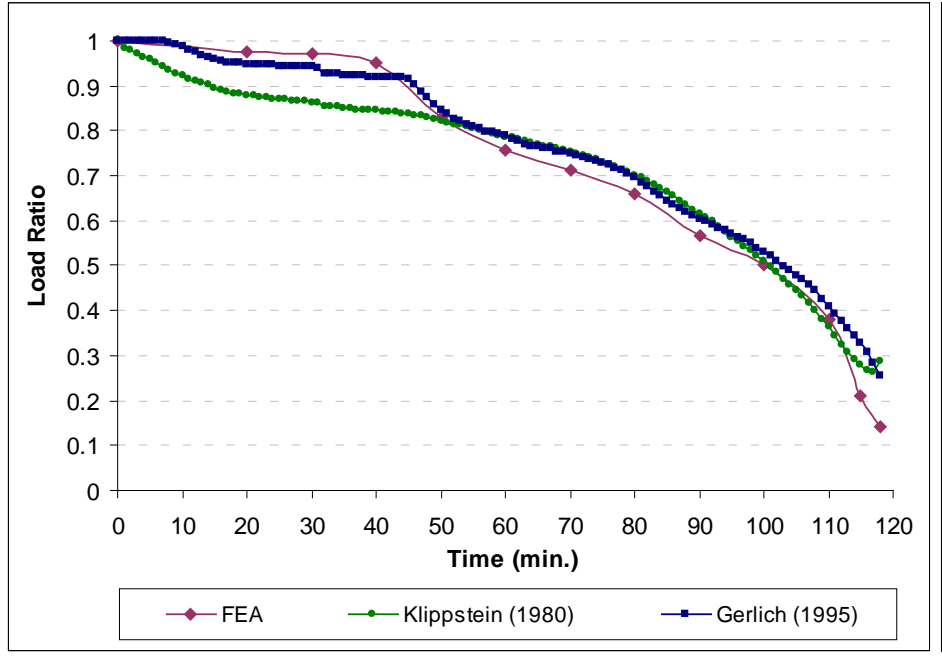

(a) Test 1

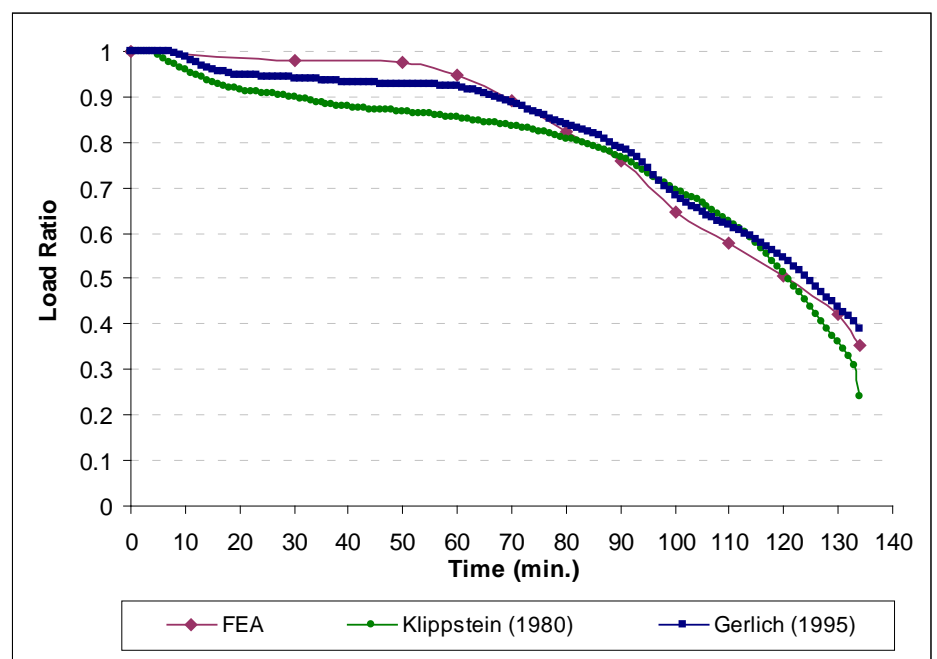

(c) Test 3

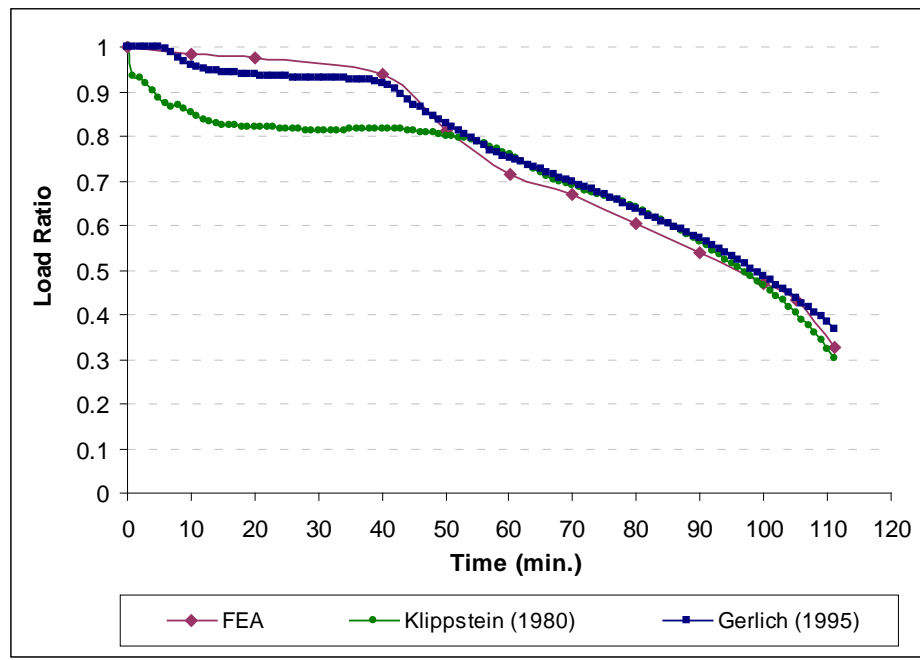

(e) Test $2^{*}$

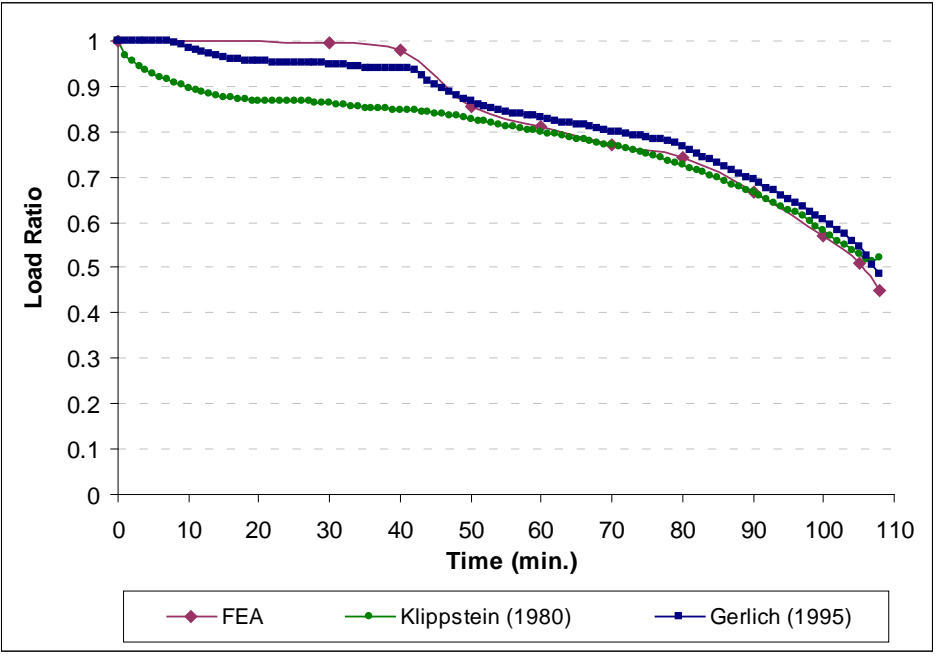

(b) Test 2

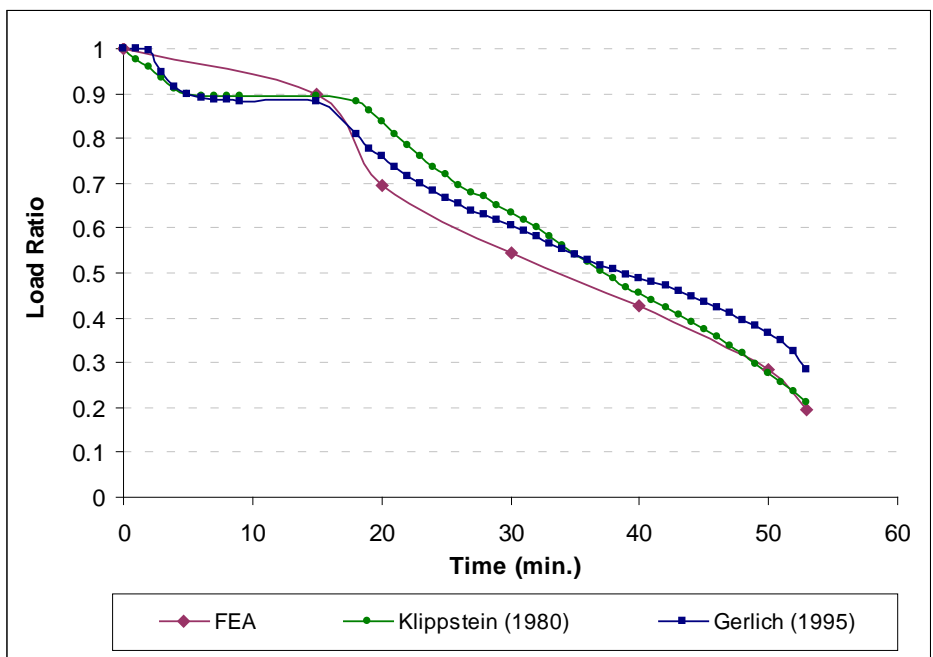

(d) Test $1 *$

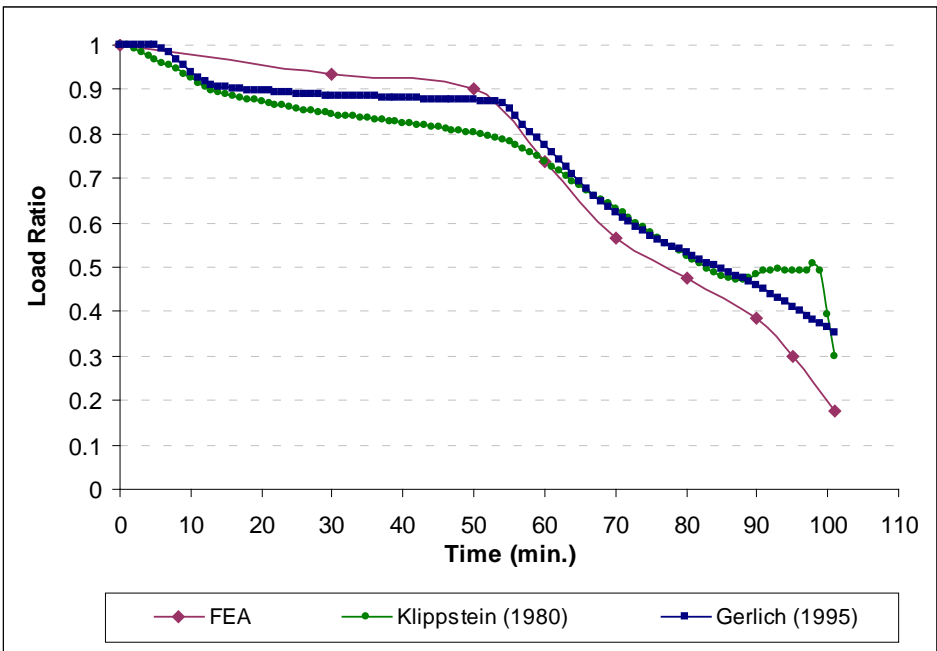

(f) Test 3*

Figure 8: Load Ratio versus Time Curves from FEA, Klippstein [1] and Gerlich et al. [2] 


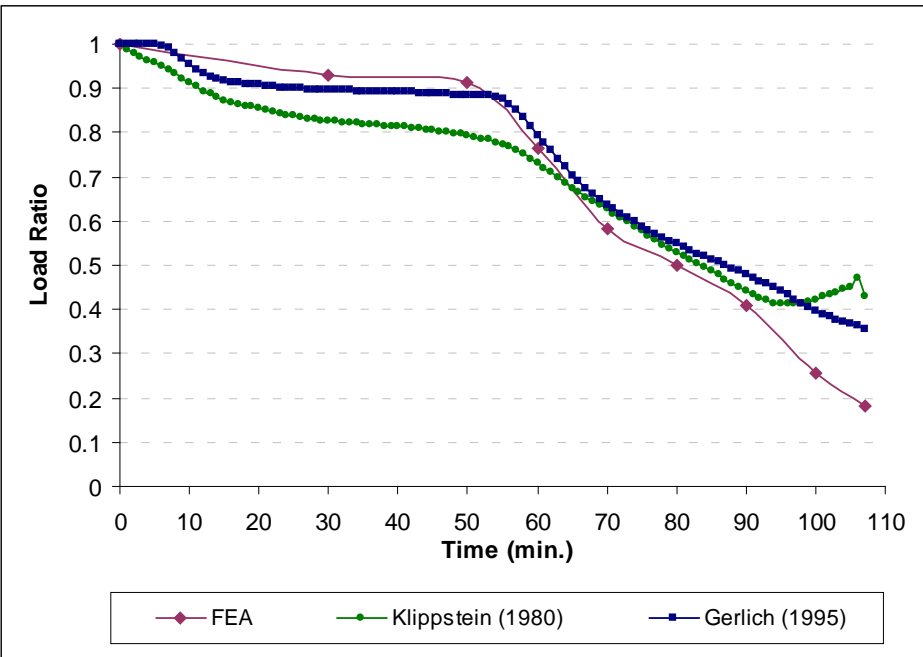

(g) Test 4*

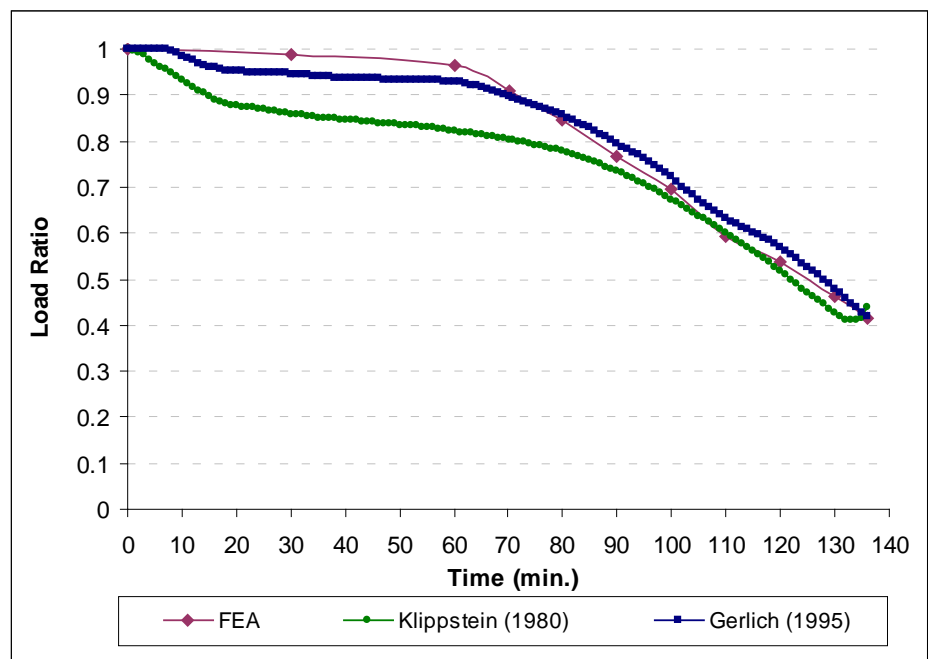

(i) Test 6*

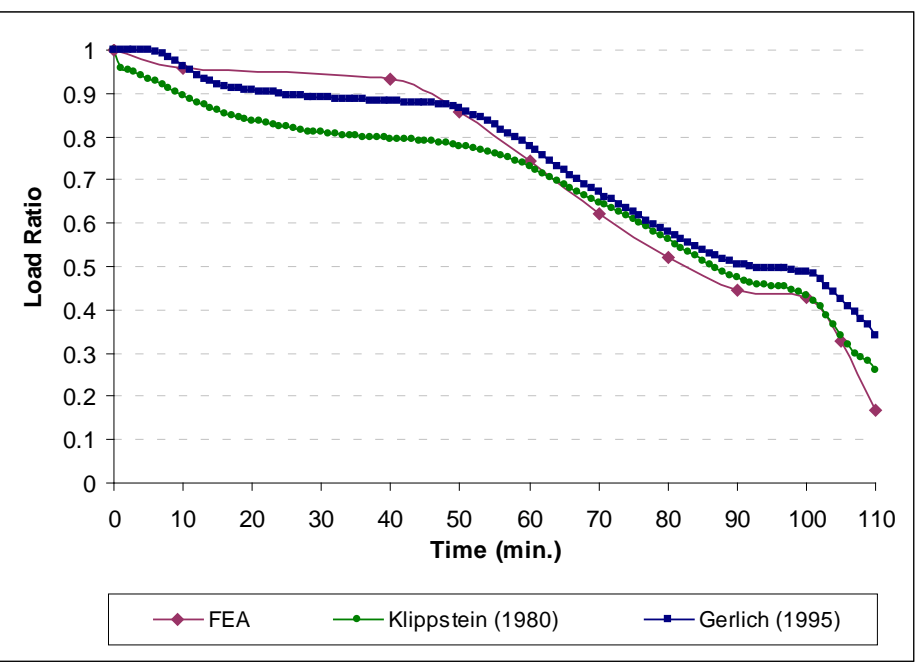

(h) Test 5*

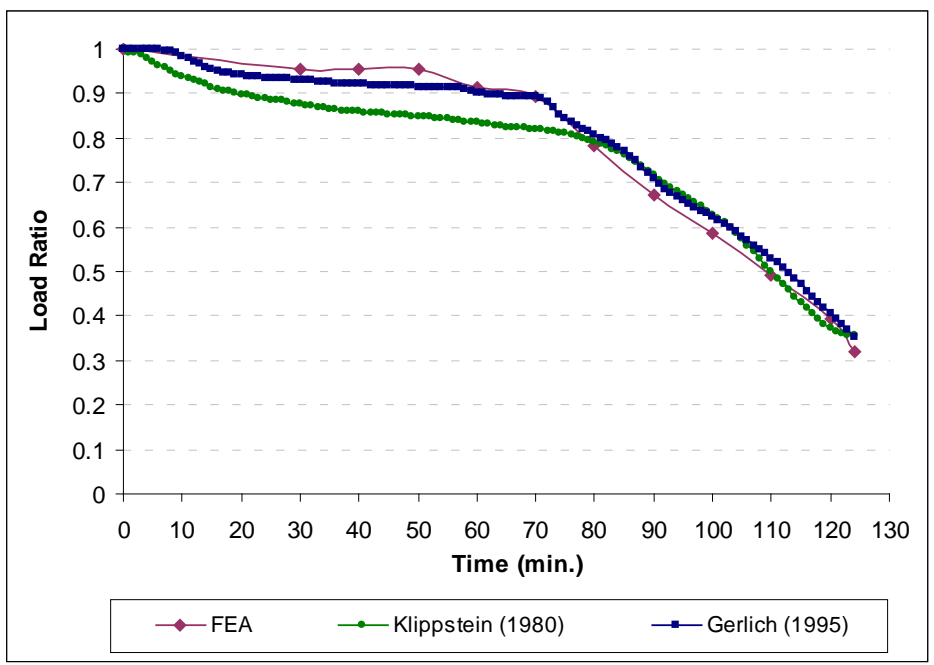

(j) Test $7^{*}$

Figure 8: Load Ratio versus Time Curves from FEA, Klippstein [1] and Gerlich et al. [2] 


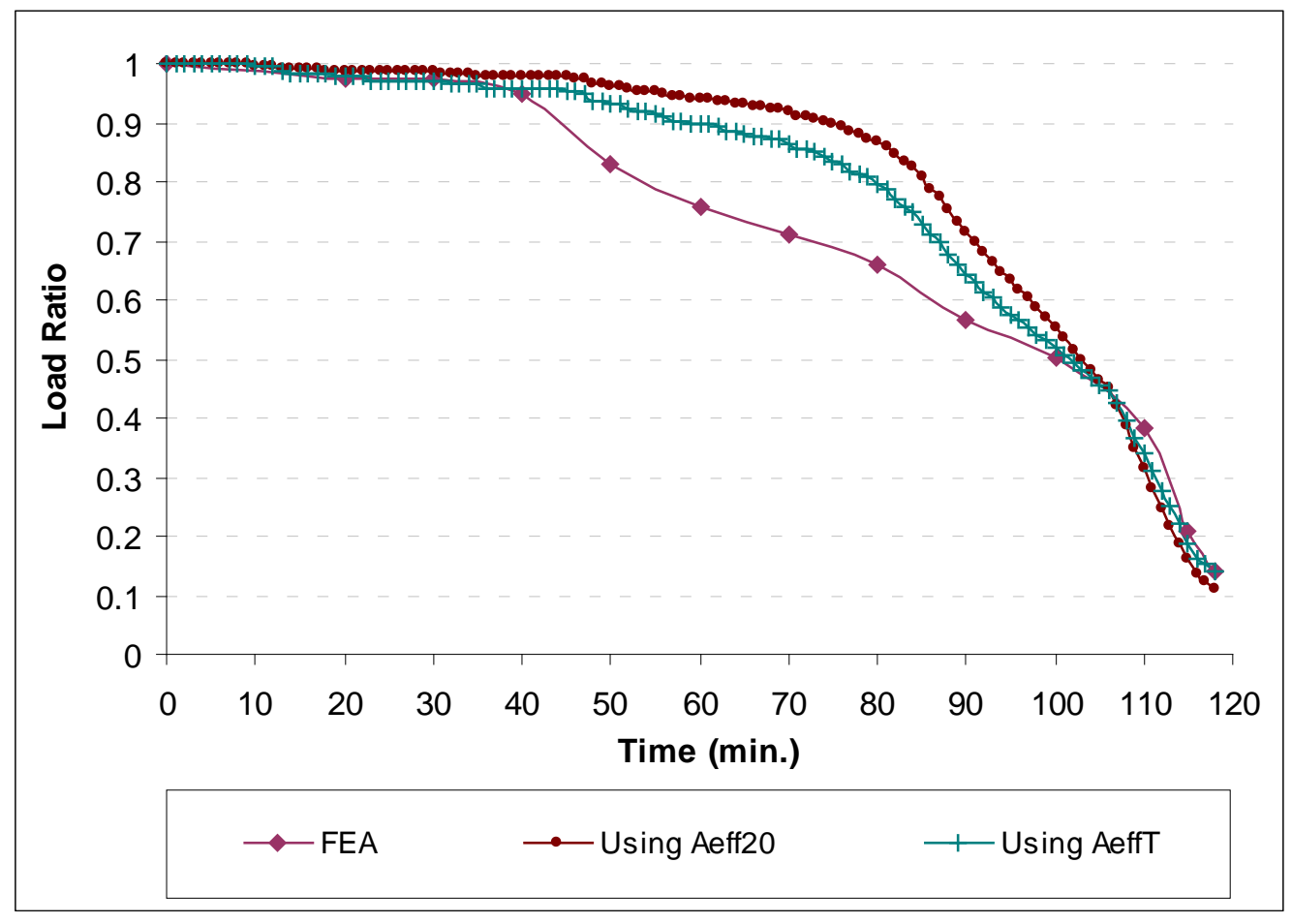

Figure 9: Influence of Effective Area in Kaitila's [5] Uniform Temperature Method for Test 1 


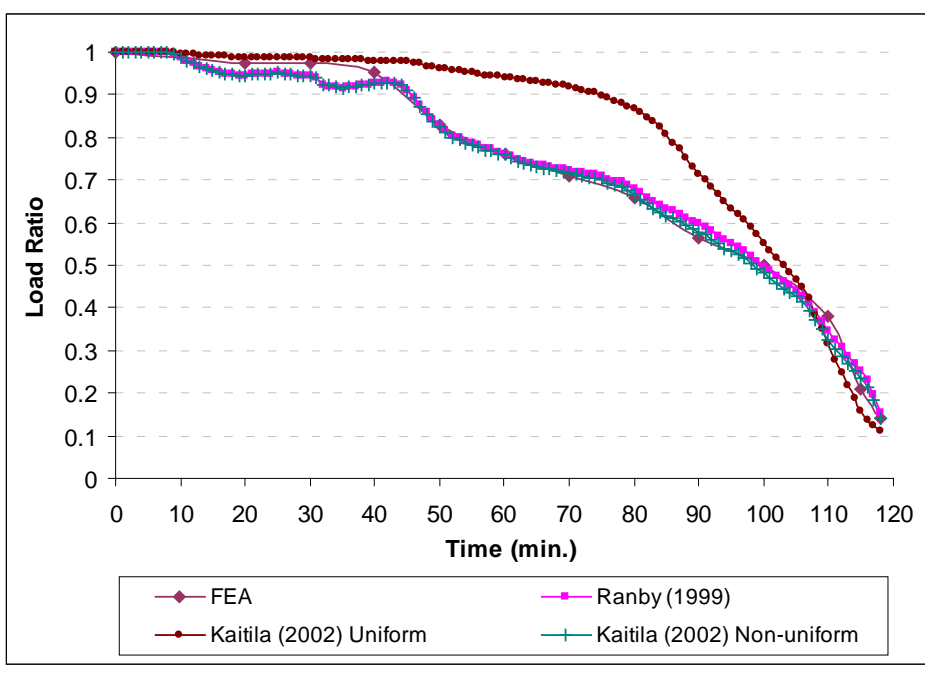

(a) Test 1

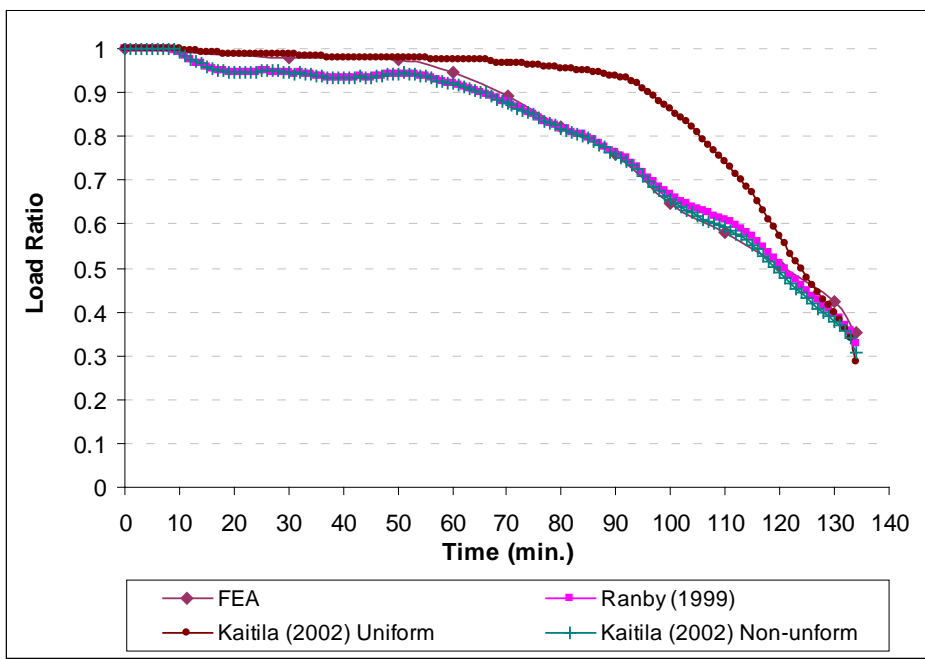

(c) Test 3

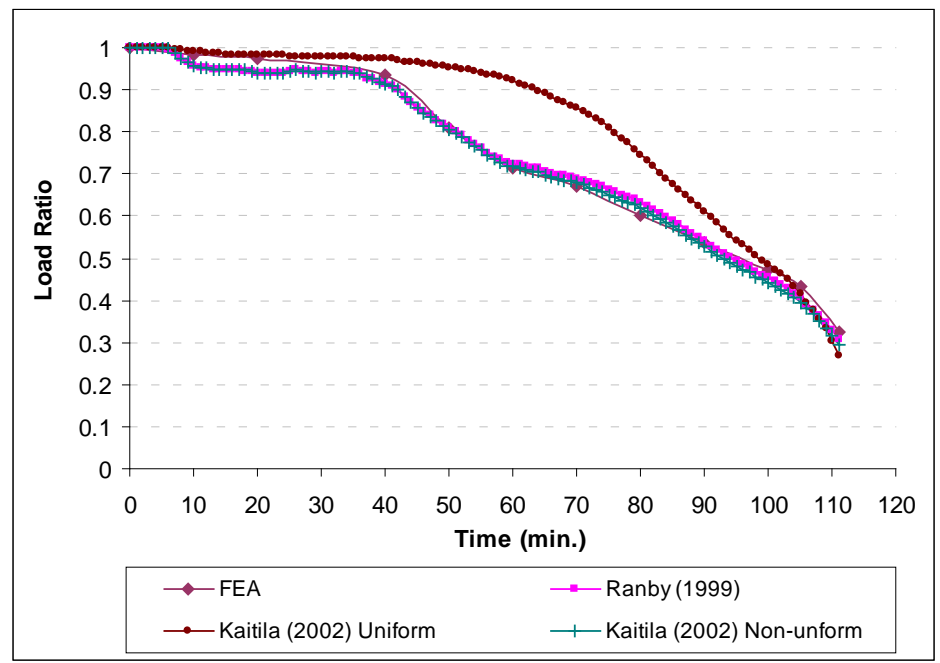

(e) Test 2*

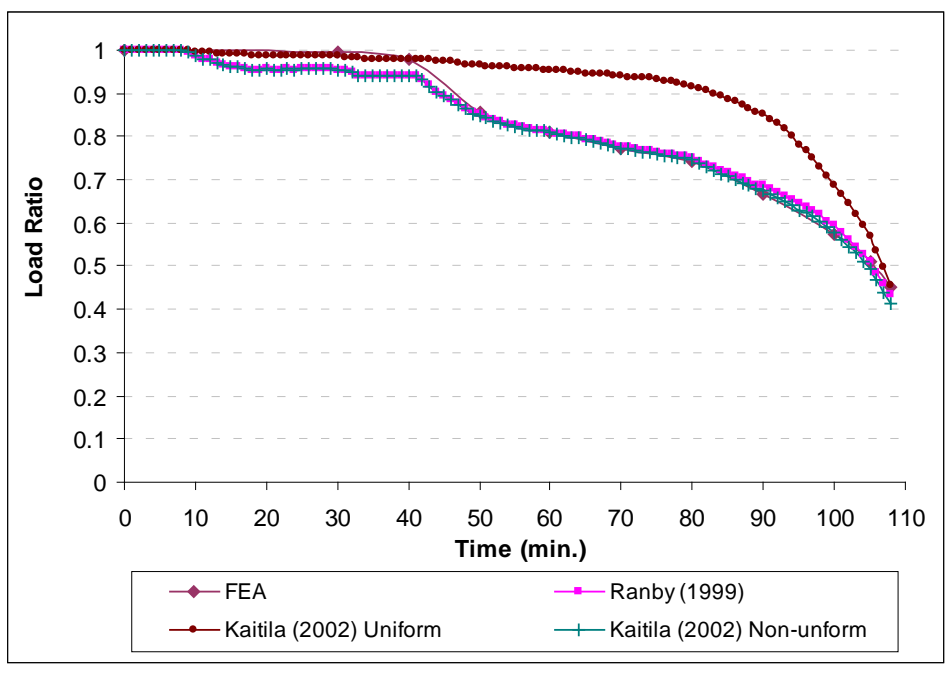

(b) Test 2

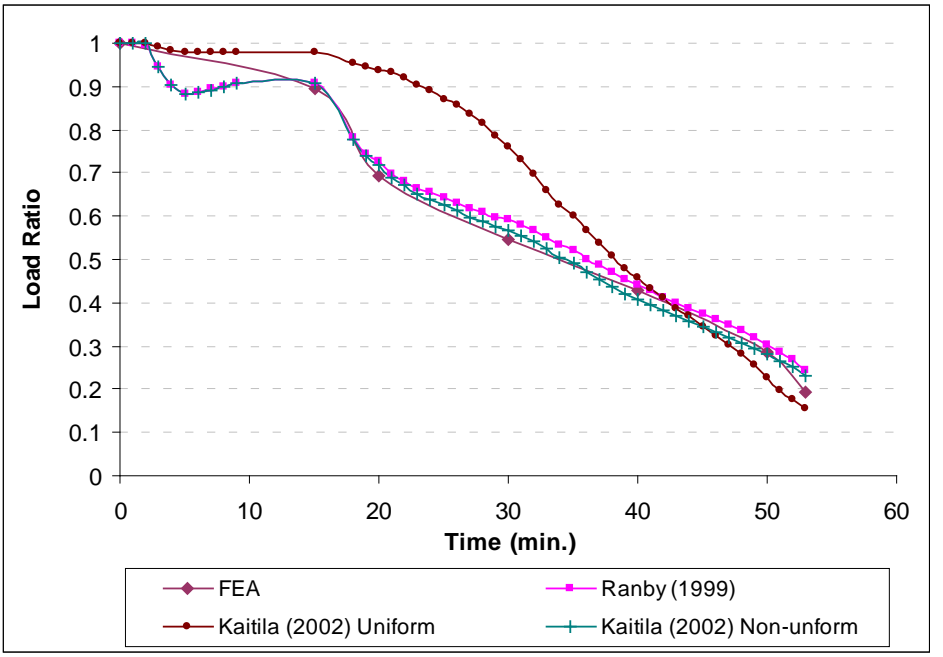

(d) Test $1^{*}$

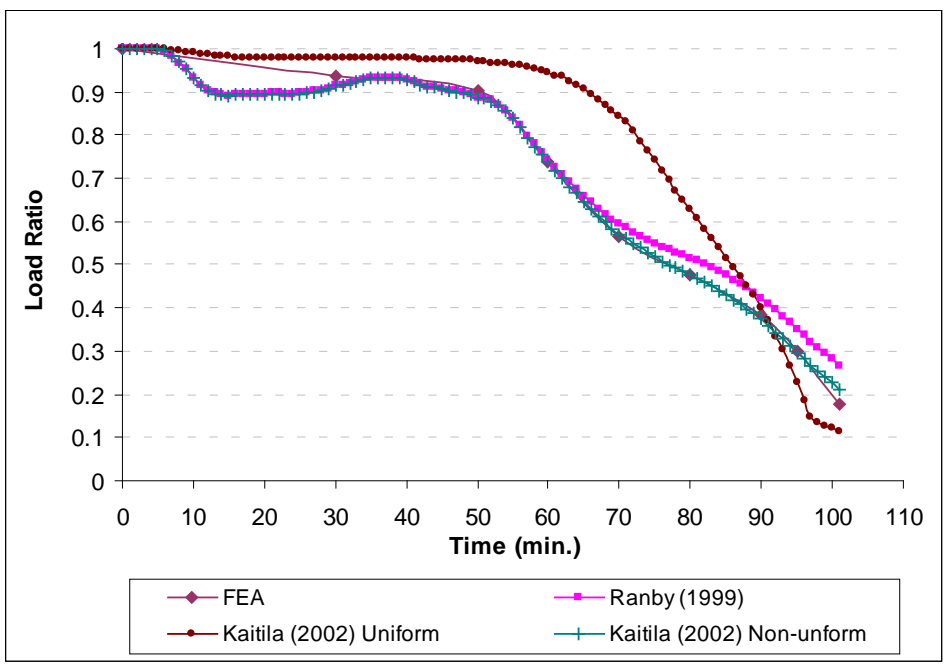

(f) Test 3*

Figure 10: Load Ratio versus Time Curves from FEA, Ranby [3] and Kaitila [5] 


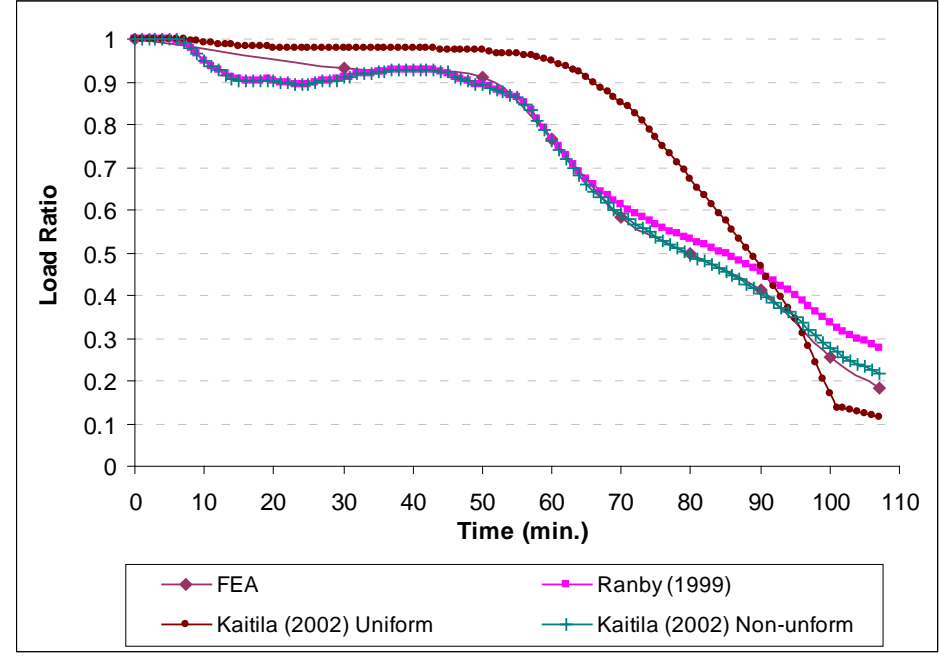

(g) Test 4*

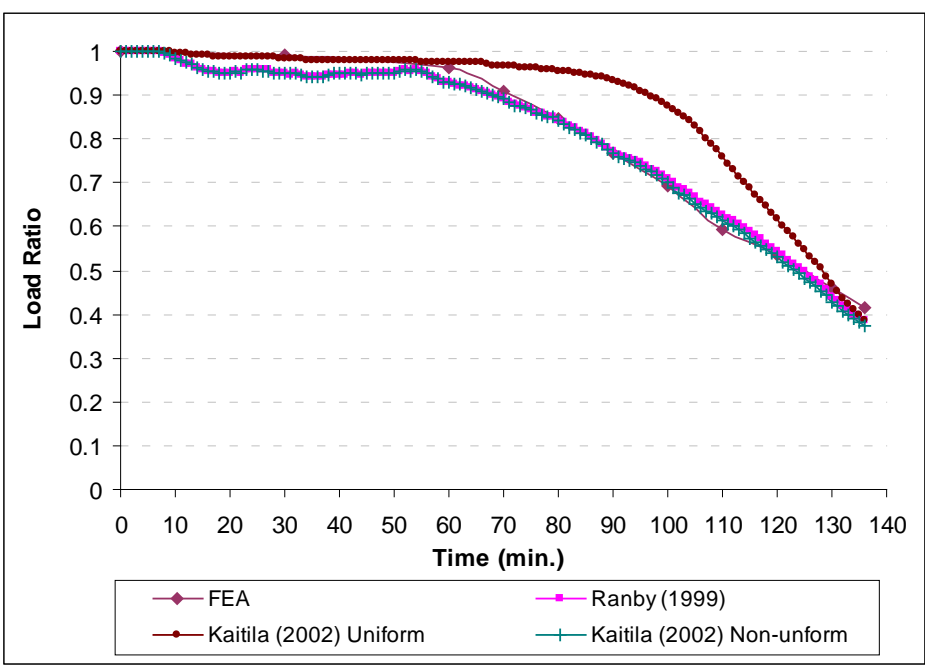

(i) Test 6*

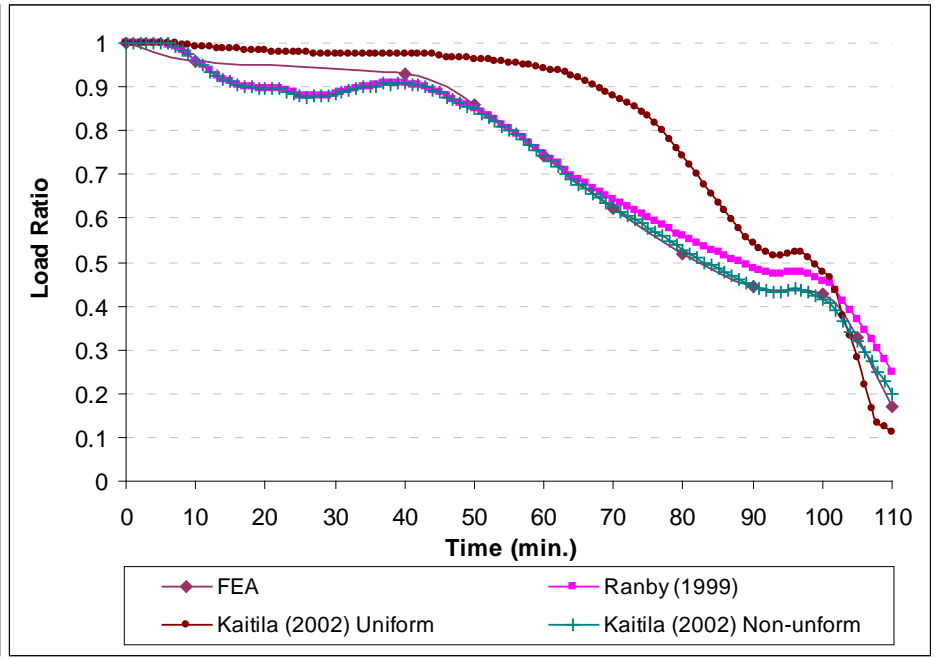

(h) Test 5*

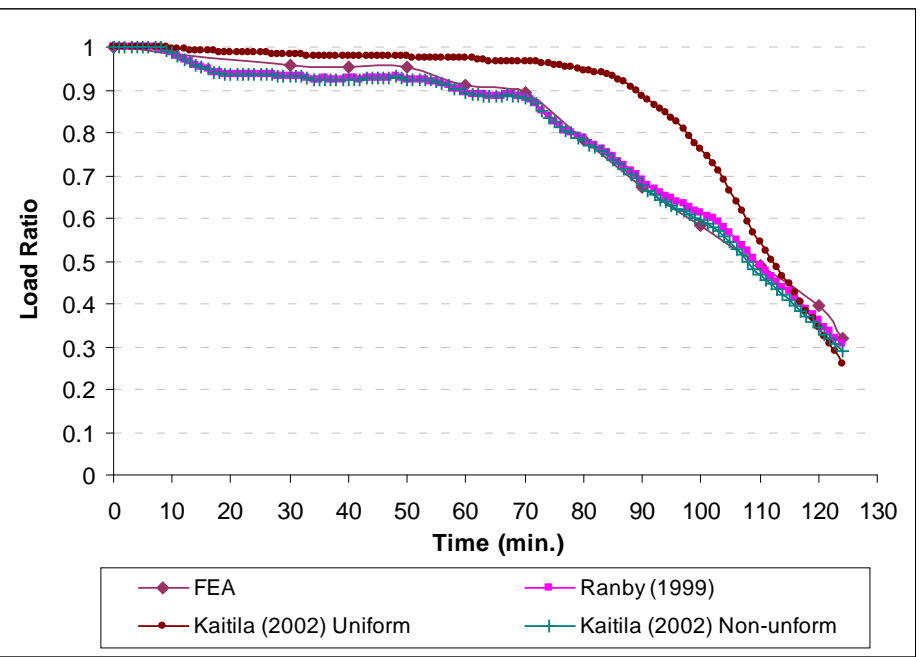

(j) Test 7*

Figure 10: Load Ratio versus Time Curves from FEA, Ranby [3] and Kaitila [5] 


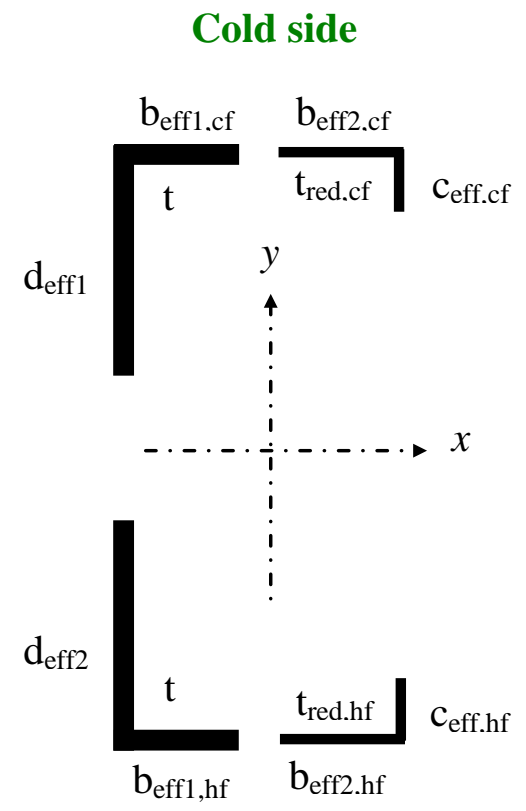

Hot side

Figure 11: Effective Cross-section of LSF Wall Stud 


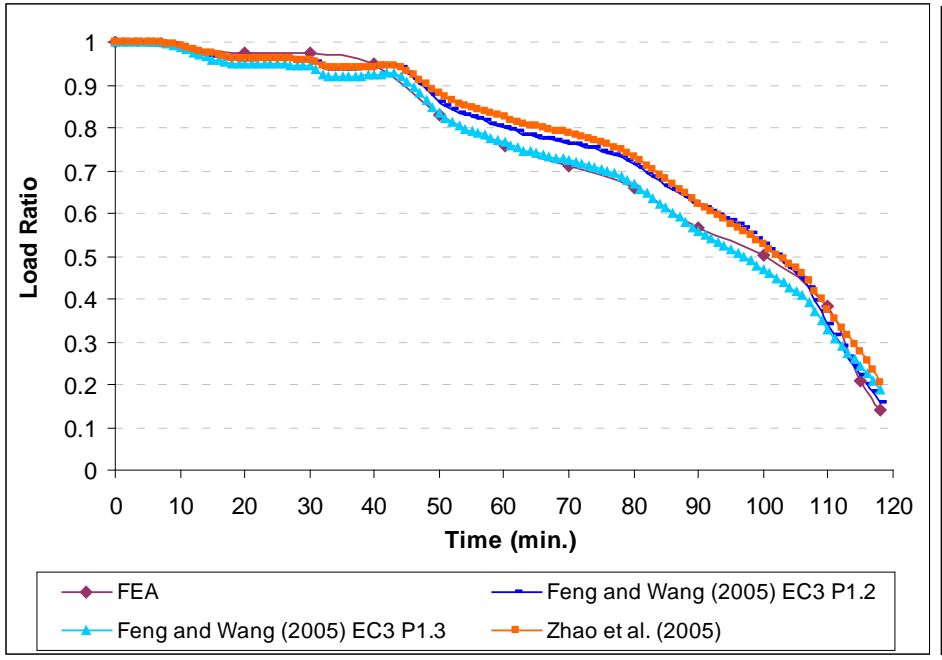

(a) Test 1

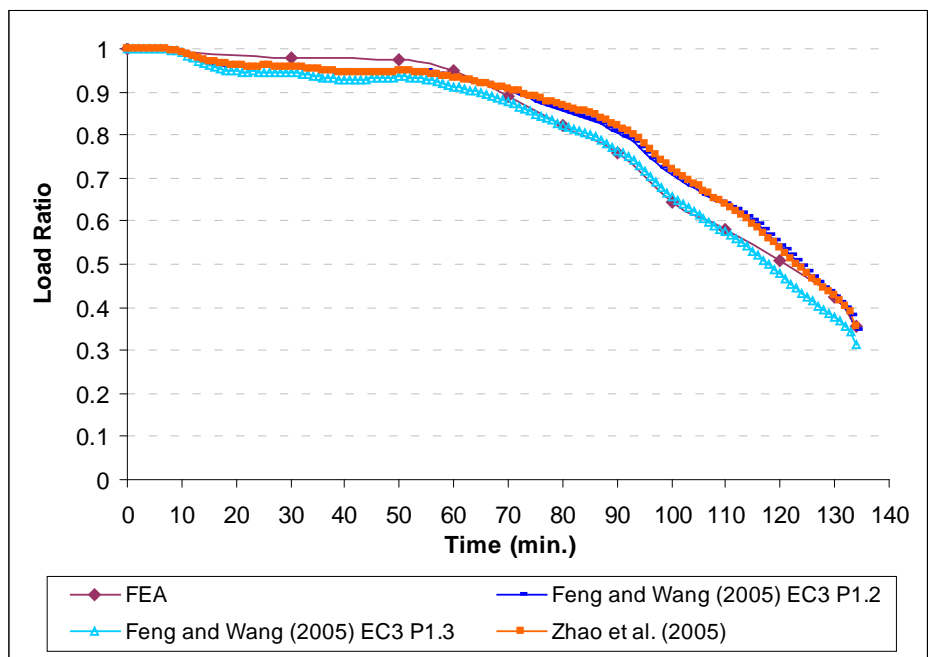

(c) Test 3

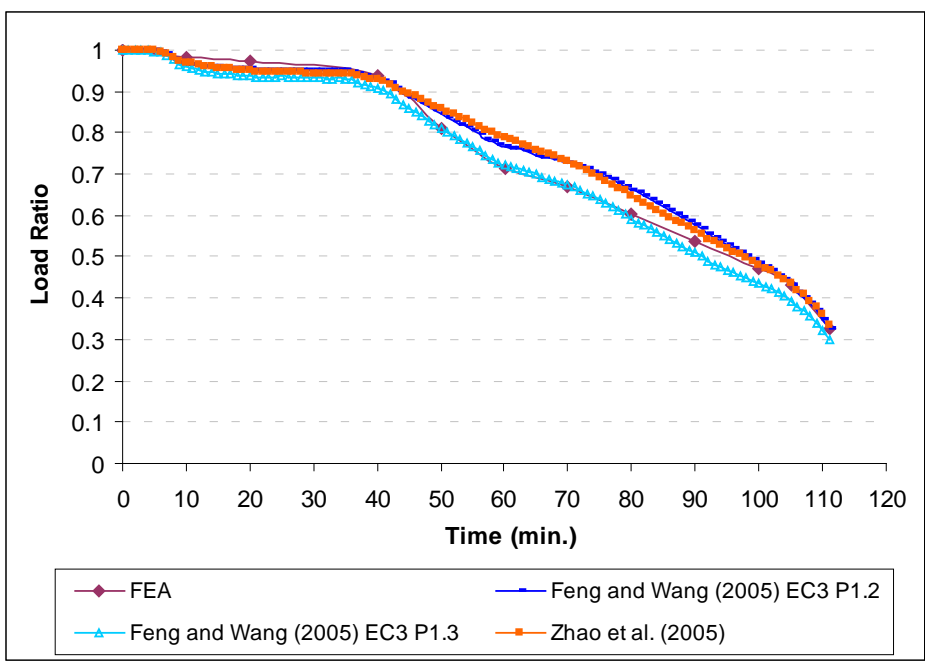

(e) Test 2*

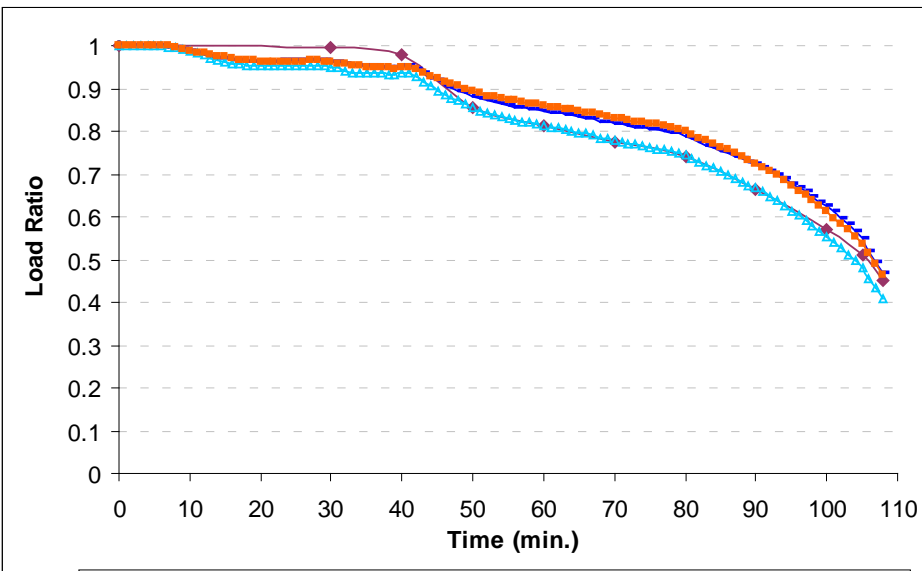

$\longrightarrow$ - FEA — Feng and Wang (2005) EC3 P1.2

(b) Test 2

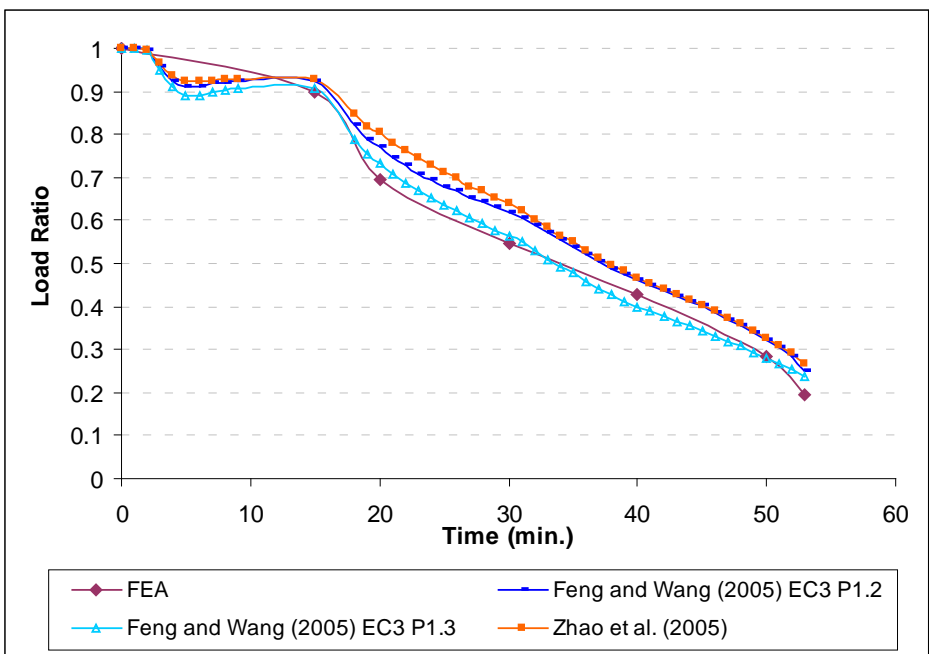

(d) Test $1^{*}$

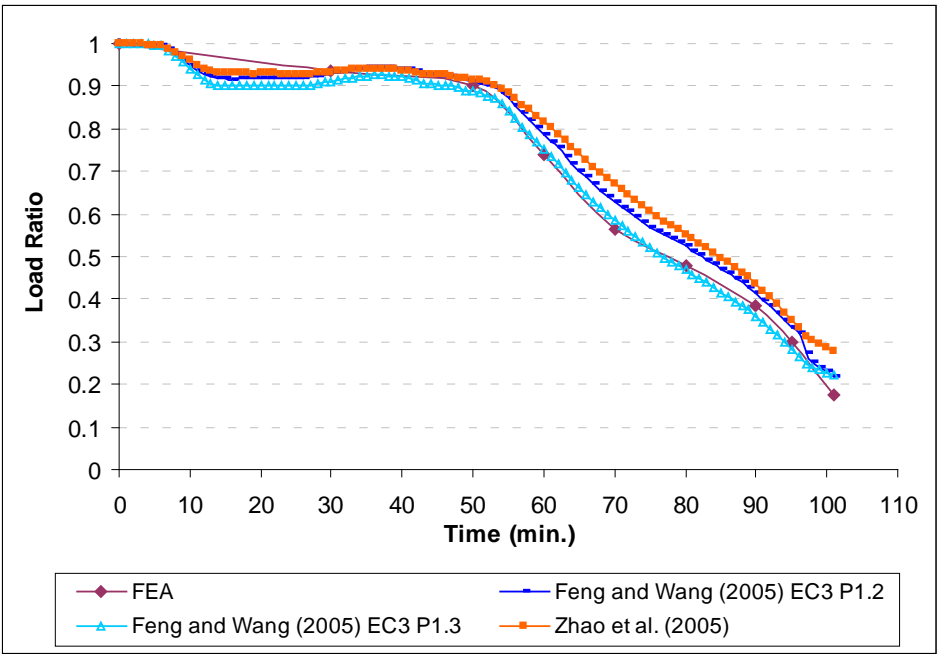

(f) Test $3 *$

Figure 12: Load Ratio versus Time Curves from FEA, Feng and Wang [6] and Zhao et al. [7] 


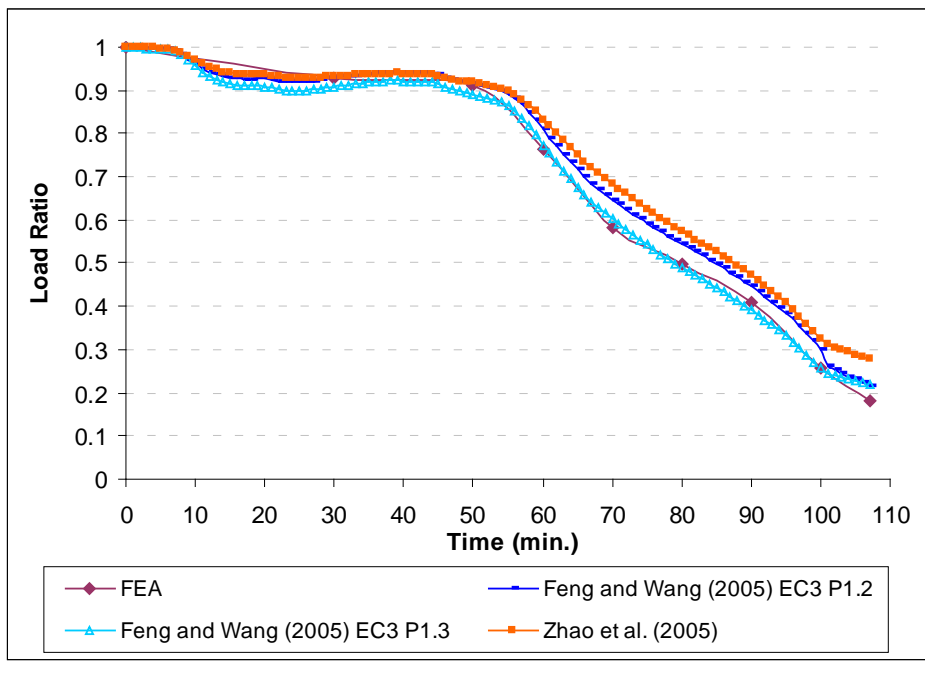

(g) Test 4*

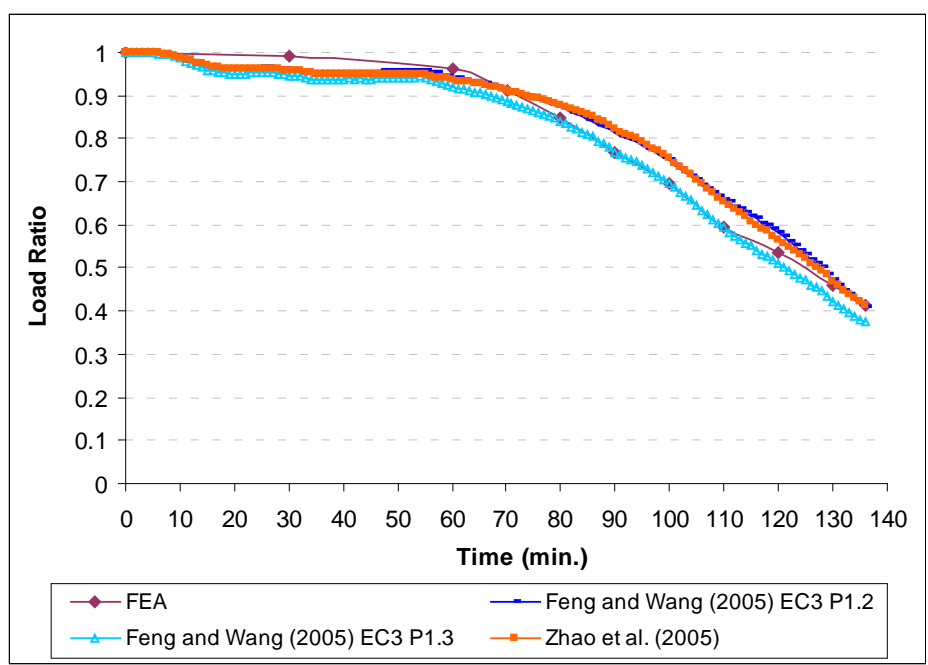

(i) Test $6 *$

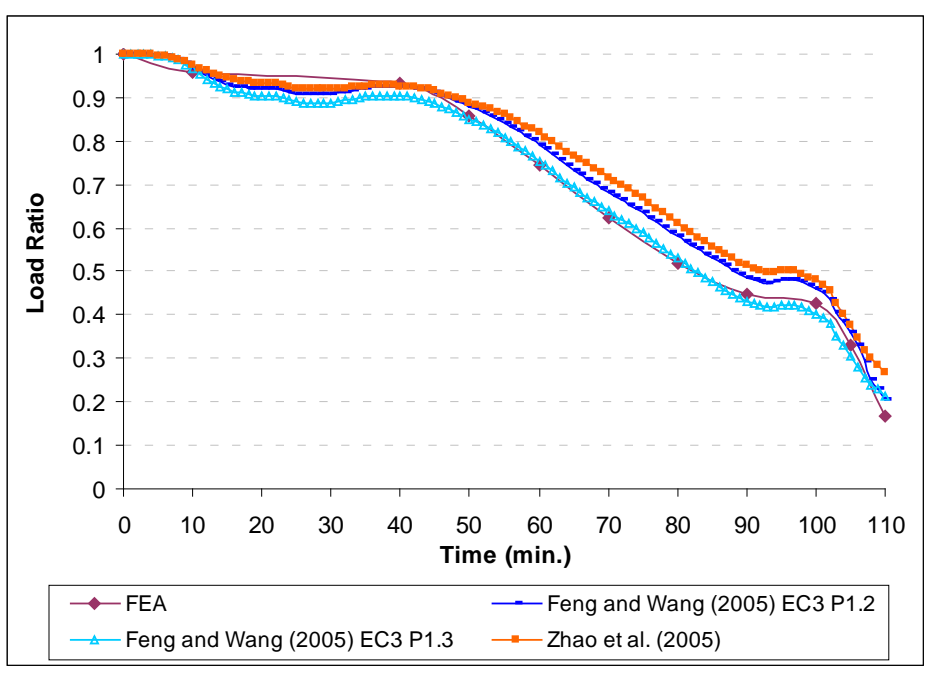

(h) Test 5*

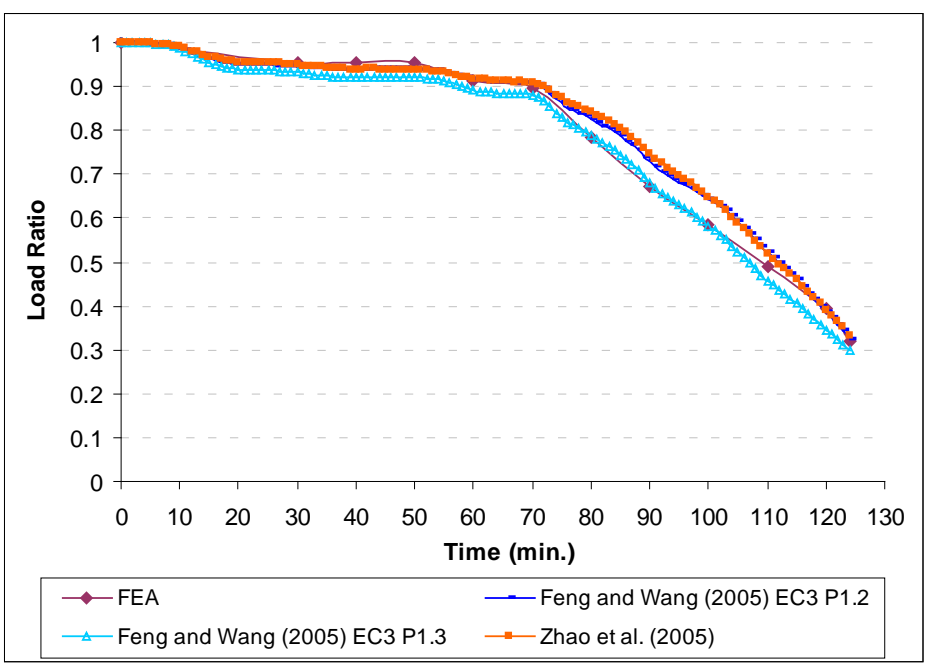

(j) Test 7*

Figure 12: Load Ratio versus Time Curves from FEA, Feng and Wang [6] and Zhao et al. [7] 


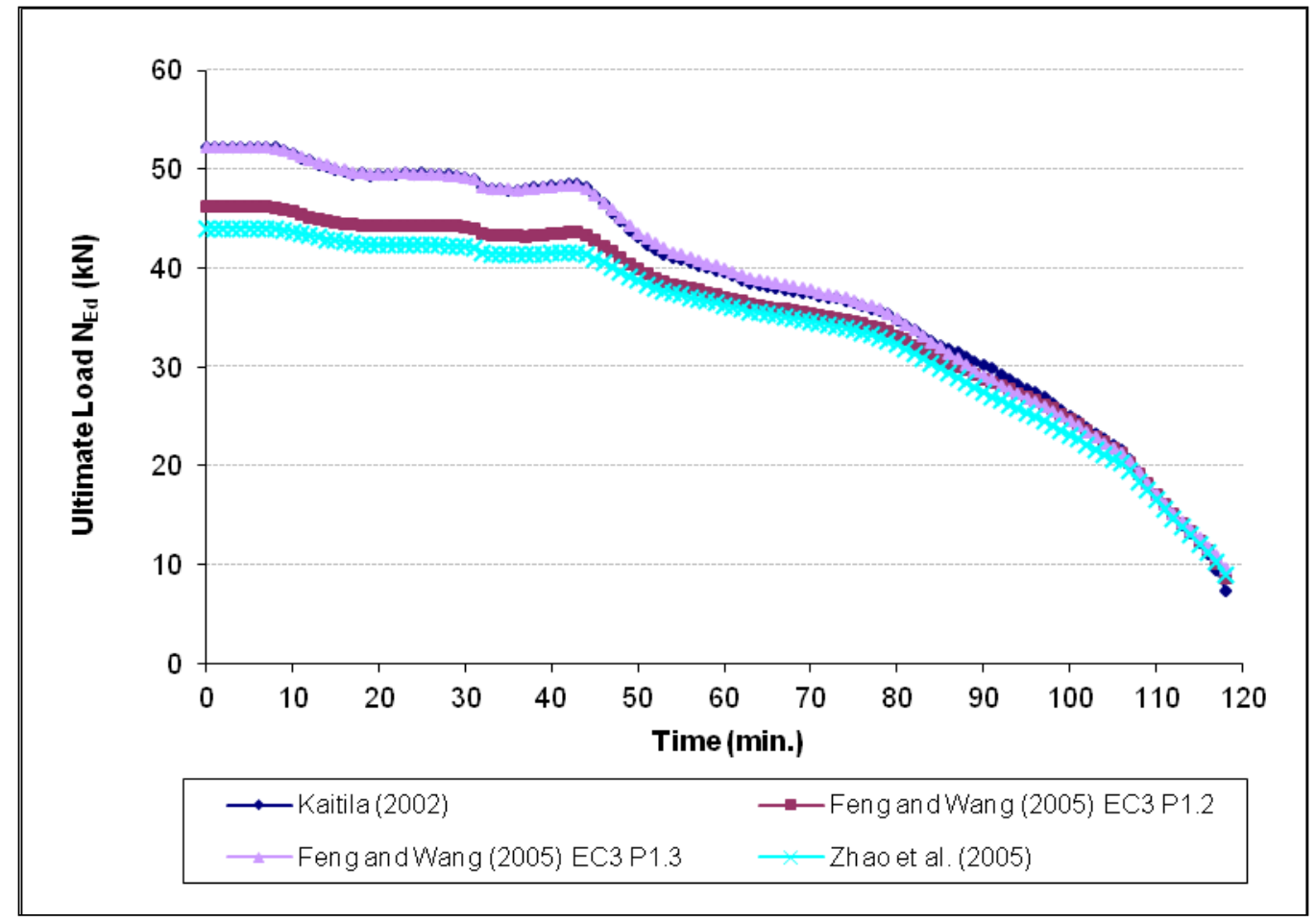

Figure 13: Variation of Ultimate Load with Time from Previous Fire Design Rules for Test 1 


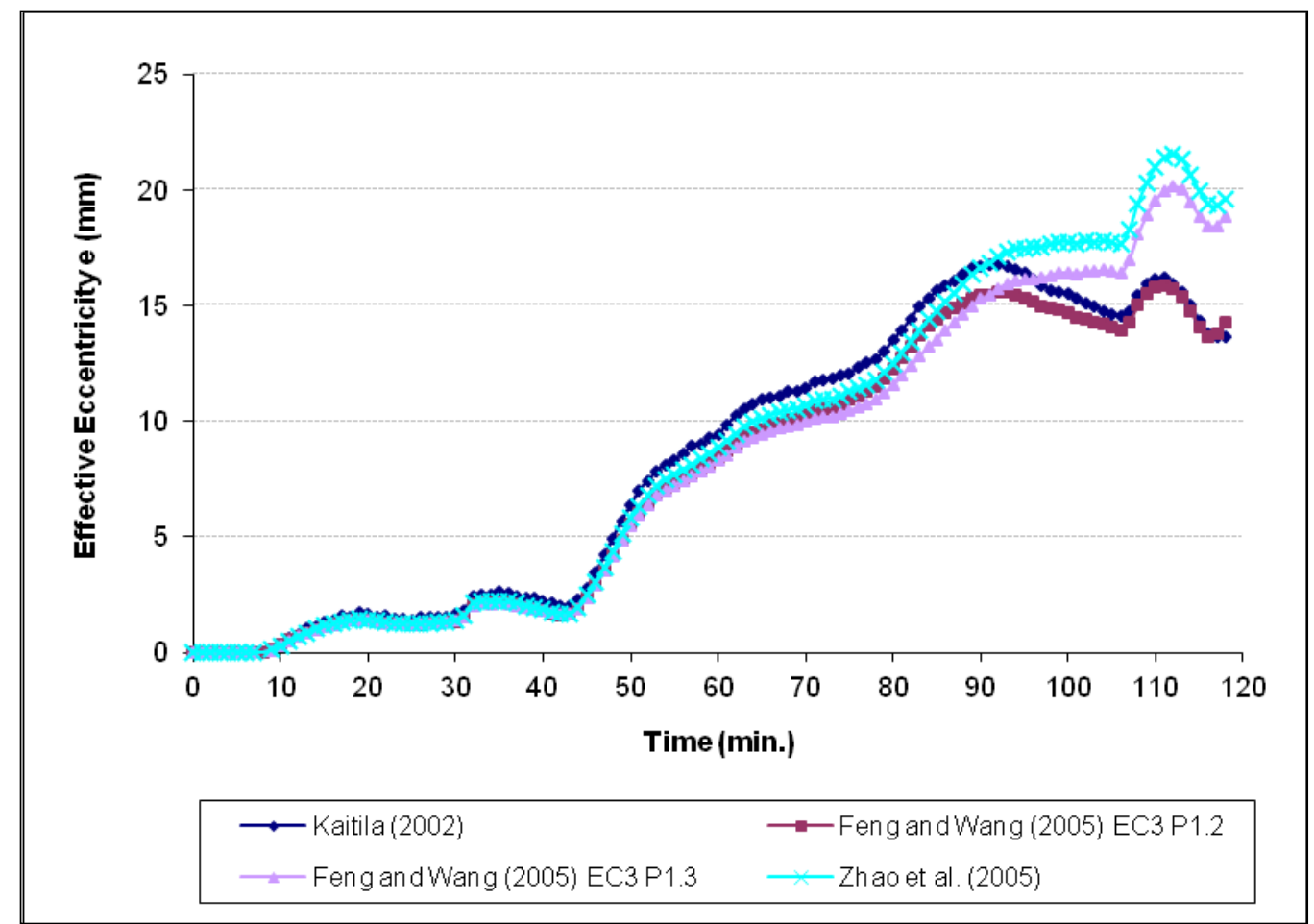

Figure 14: Variation of Effective Eccentricity with Time from Previous Fire Design Rules for Test 1 


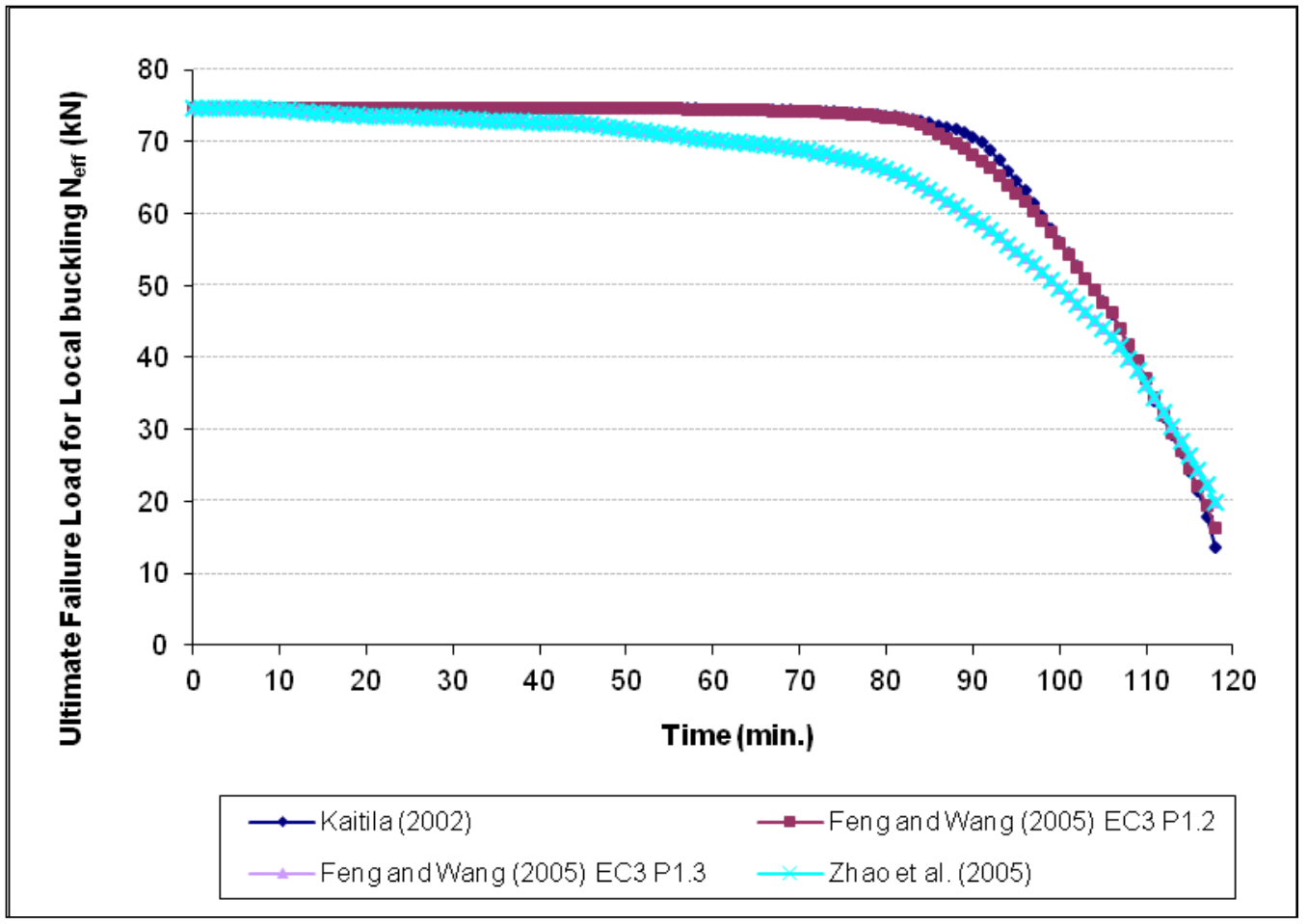

(a) Ultimate failure load

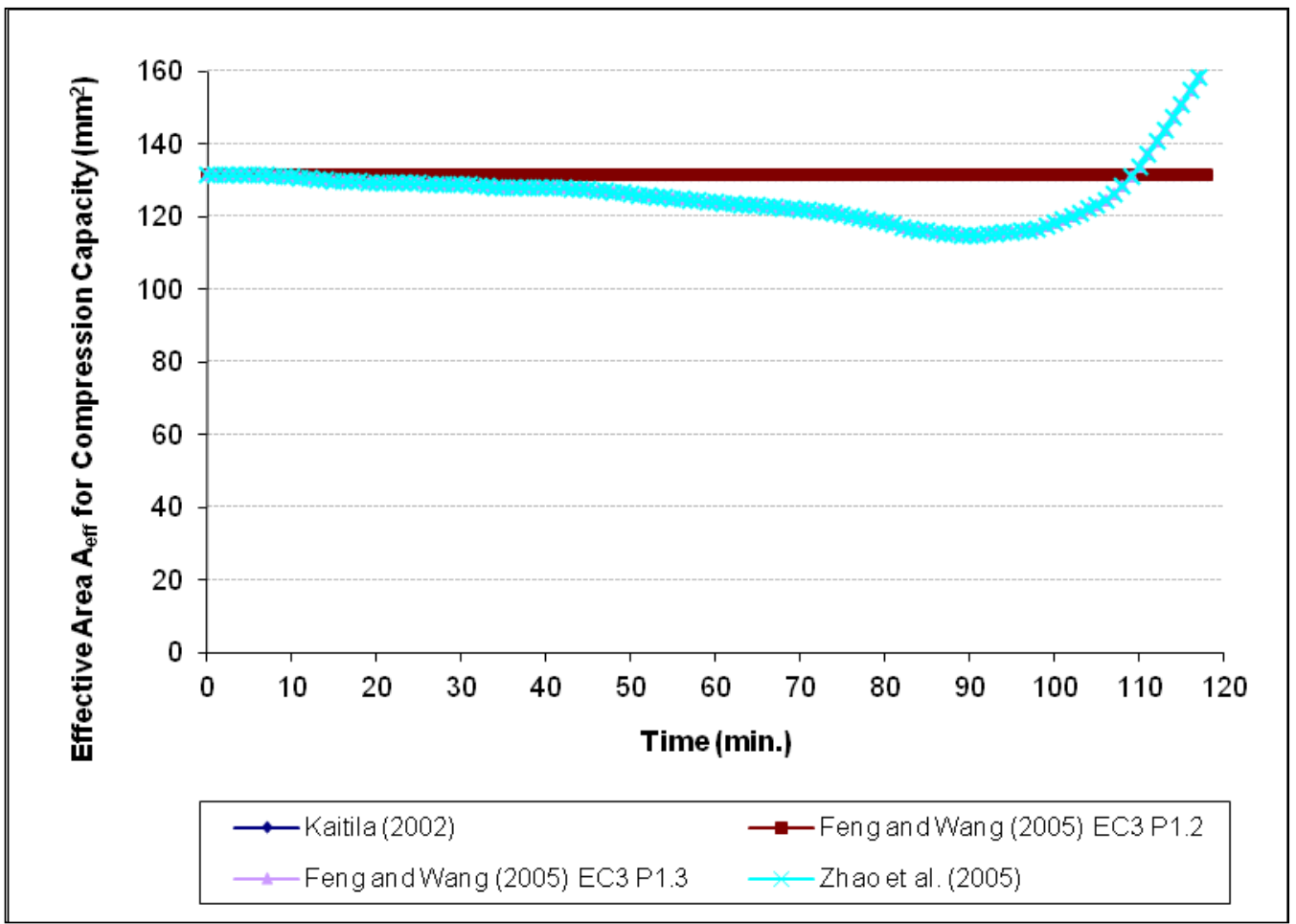

(b) Effective area

Figure 15: Variation of Local Buckling Capacity and Corresponding Effective Area with Time from Previous Fire Design Rules for Test 1 


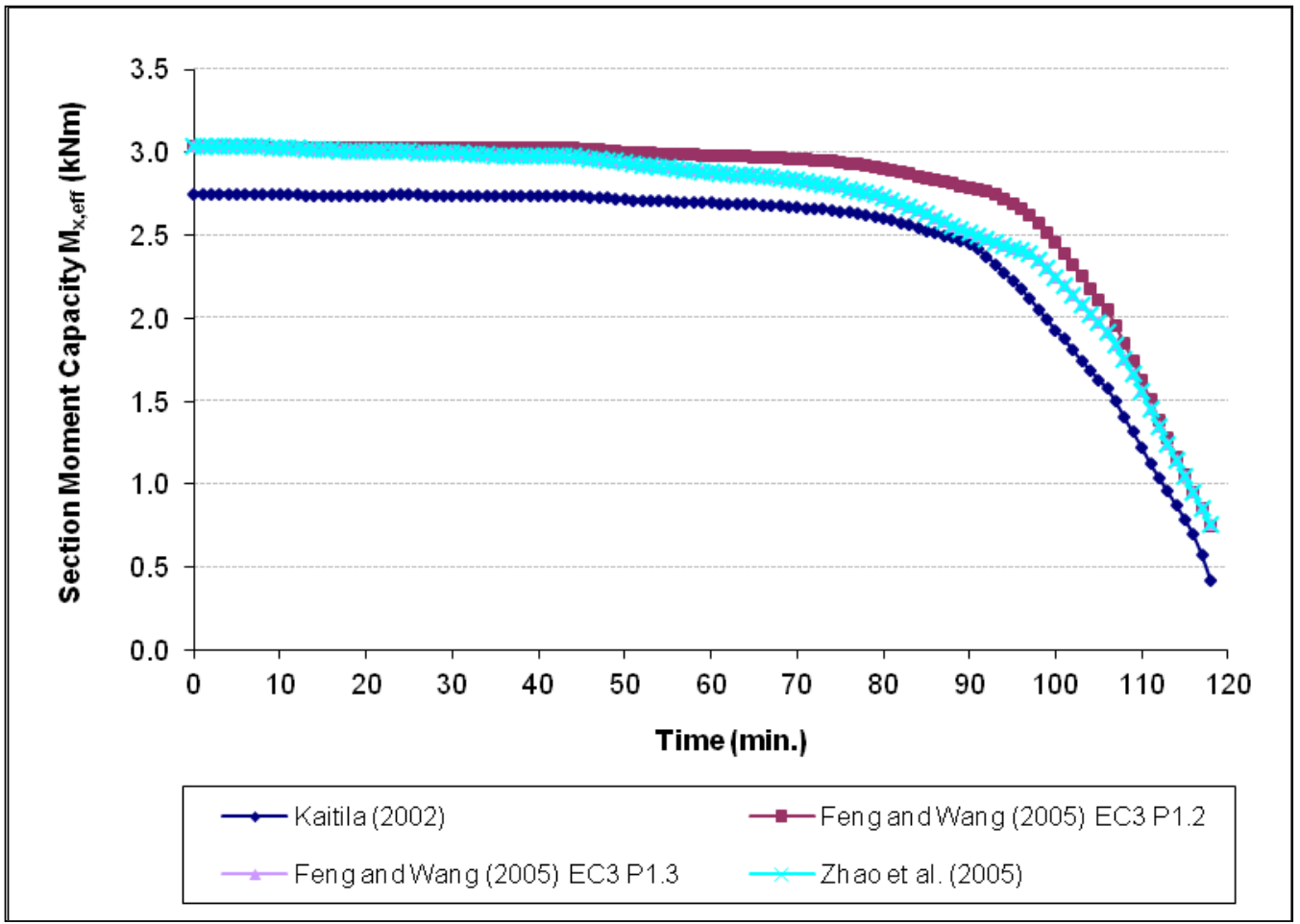

(a) Section moment capacity

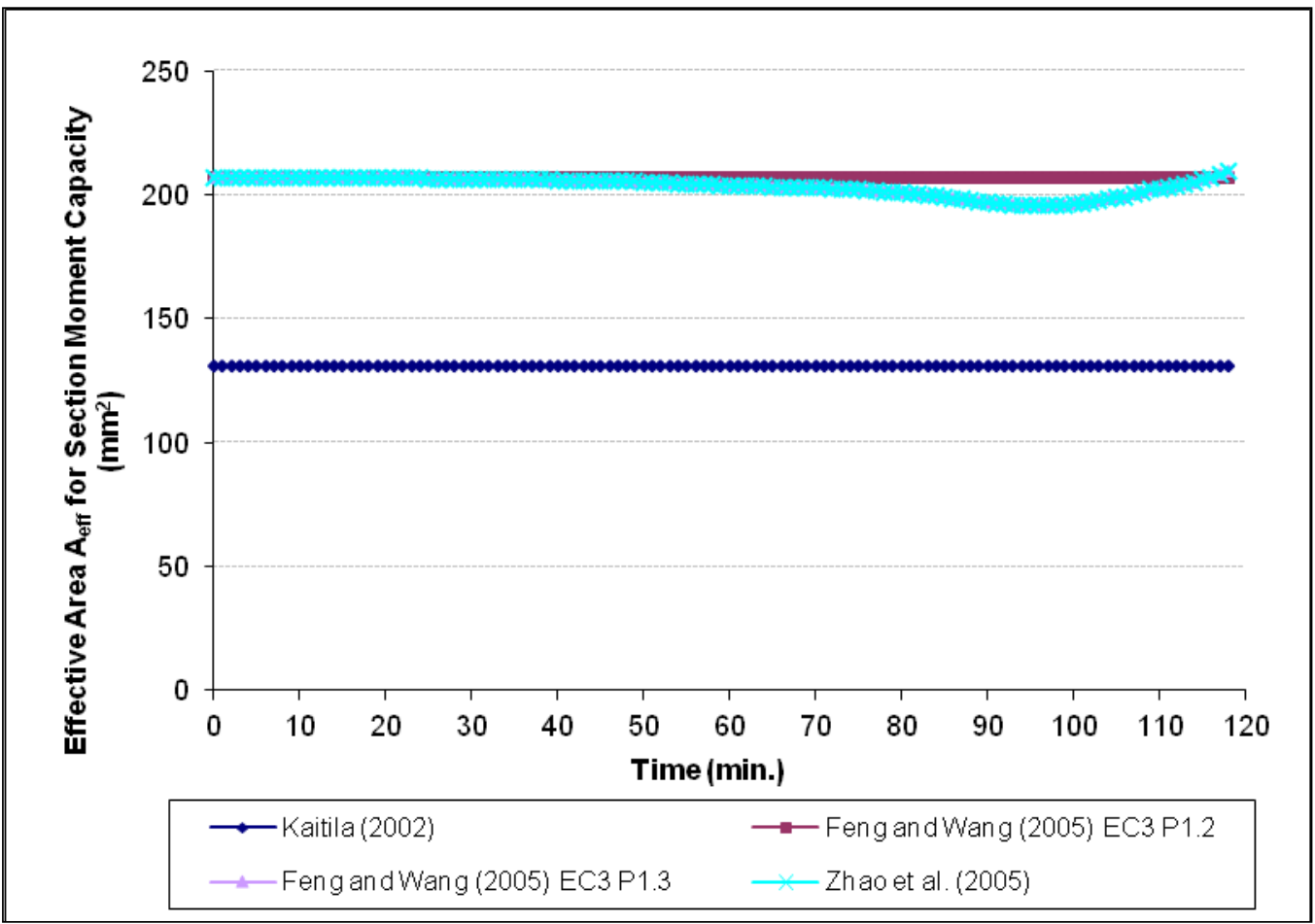

(b) Effective area

Figure 16: Variation of Section Moment Capacity and Corresponding Effective Area with Time from Previous Fire Design Rules for Test 1 


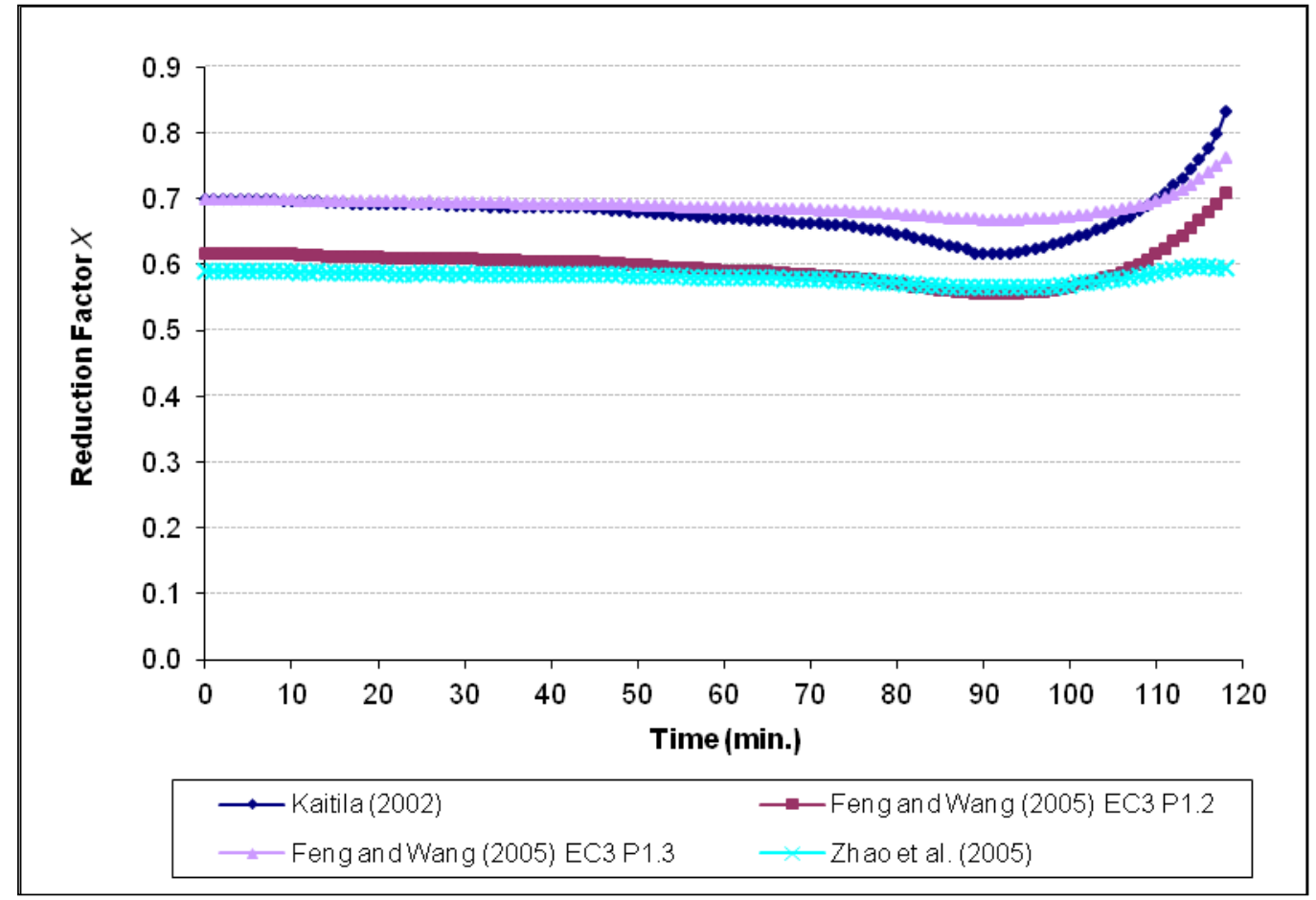

(a) Reduction factor $\chi_{x}$

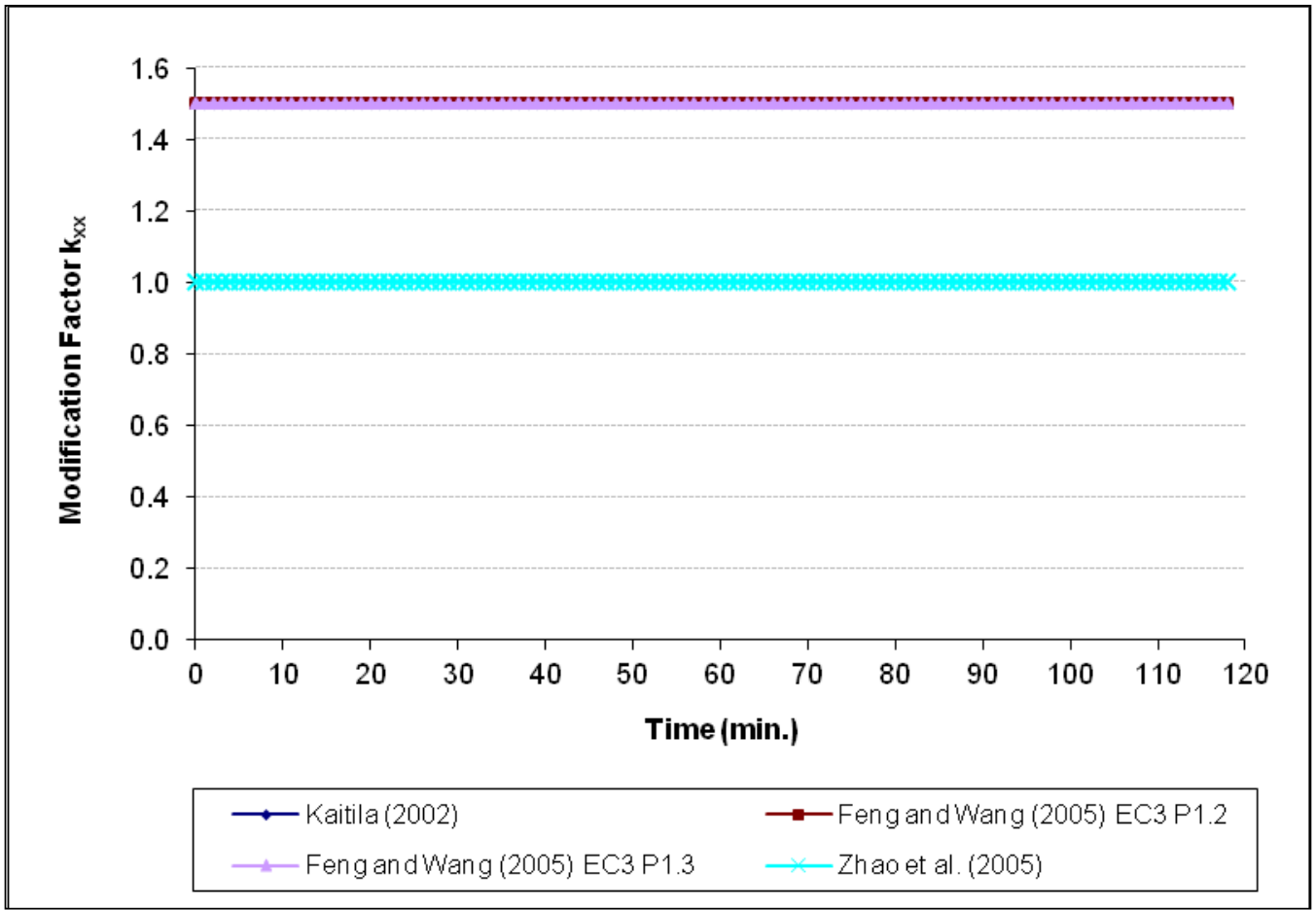

(b) Reduction factor $k_{x x}$

Figure 17: Variation of Reduction Factors with Time from Previous Fire Design Rules for Test 1 
Table 1: Failure Times from Fire Tests and FEA

\begin{tabular}{|c|c|c|c|c|c|c|}
\hline \multirow{2}{*}{ Test } & \multirow{2}{*}{ Configuration } & \multirow{2}{*}{ Insulation } & \multirow{2}{*}{ Layout } & \multirow{2}{*}{$\begin{array}{l}\text { Load } \\
\text { Ratio }\end{array}$} & \multicolumn{2}{|c|}{ Failure Time (min.) } \\
\hline & & & & & Test & FEA \\
\hline 1 & $\begin{array}{llll} \\
\end{array}$ & Glass Fibre & External & 0.2 & 118 & 115 \\
\hline 2 & 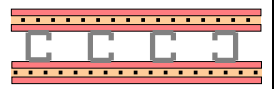 & Glass Fibre & External & 0.4 & 108 & 110 \\
\hline 3 & 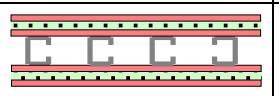 & Rock Fibre & External & 0.4 & 134 & 131 \\
\hline $1^{*}$ & $\begin{array}{lllll} & {[} & {[} & \\
\end{array}$ & None & - & 0.2 & 53 & 53 \\
\hline $2 *$ & L L L & None & - & 0.2 & 111 & 115 \\
\hline $3^{*}$ & $\therefore \because \because 6$ & Glass Fibre & Cavity & 0.2 & 101 & 100 \\
\hline $4^{*}$ & a $\because \because \mathrm{O}$ & Rock Fibre & Cavity & 0.2 & 107 & 105 \\
\hline $5^{*}$ & $\because \because \cdots$ & Cellulose Fibre & Cavity & 0.2 & 110 & 109 \\
\hline $6^{*}$ & $\begin{array}{ll}\mathrm{L} \\
\mathrm{L}\end{array}$ & Rock Fibre & External & 0.2 & $136^{\#}$ & 154 \\
\hline $7^{*}$ & $\begin{array}{lllll}{ }_{1} & \\
\end{array}$ & Cellulose Fibre & External & 0.2 & 124 & 129 \\
\hline
\end{tabular}

Tests 1 - 3 : conducted by Gunalan [10]

Tests $1 *-7 *$ : conducted by Kolarkar [9]

(\# ) - Earlier failure time due to lack of space for thermal expansion 
Table 2: Effective Areas for Previous Fire Design Rules

\begin{tabular}{|c|c|c|}
\hline $\begin{array}{l}\text { Previous Fire } \\
\text { design Rules }\end{array}$ & $\begin{array}{c}\text { Effective Area for } \\
\text { Compression Capacity }\end{array}$ & $\begin{array}{c}\text { Section Modulus } \mathrm{Z}_{\mathrm{eff}} \text { for } \\
\text { Bending Capacity }\end{array}$ \\
\hline Klippstein [1] & $\begin{array}{l}\text { Effective area was calculated } \\
\text { assuming uniform compression } \\
\text { at elevated temperatures }\end{array}$ & Gross area was used \\
\hline $\begin{array}{c}\text { Gerlich et al. } \\
\text { [2] }\end{array}$ & $\begin{array}{l}\text { Effective area was calculated } \\
\text { assuming uniform compression } \\
\text { at ambient temperatures }\end{array}$ & Gross area was used \\
\hline Ranby [3] & $\begin{array}{l}\text { Effective area was calculated } \\
\text { assuming uniform compression } \\
\text { at ambient temperatures }\end{array}$ & $\begin{array}{l}\text { Effective area was calculated } \\
\text { assuming uniform compression } \\
\text { at ambient temperatures }\end{array}$ \\
\hline Kaitila [5] & $\begin{array}{l}\text { Effective area was calculated } \\
\text { assuming uniform compression } \\
\text { at ambient temperatures }\end{array}$ & $\begin{array}{l}\text { Effective area was calculated } \\
\text { assuming uniform compression } \\
\text { at ambient temperatures }\end{array}$ \\
\hline $\begin{array}{c}\text { Feng and } \\
\text { Wang [6] } \\
\text { Eurocode } 3 \\
\text { Part } 1.2\end{array}$ & $\begin{array}{l}\text { Effective area was calculated } \\
\text { assuming uniform compression } \\
\text { at ambient temperatures }\end{array}$ & $\begin{array}{c}\text { Effective area was calculated } \\
\text { assuming pure bending at } \\
\text { ambient temperatures }\end{array}$ \\
\hline $\begin{array}{c}\text { Feng and } \\
\text { Wang [6] } \\
\text { Eurocode } 3 \\
\text { Part } 1.3\end{array}$ & $\begin{array}{l}\text { Effective area was calculated } \\
\text { assuming uniform compression } \\
\text { at elevated temperatures }\end{array}$ & $\begin{array}{c}\text { Effective area was calculated } \\
\text { assuming pure bending at } \\
\text { elevated temperatures }\end{array}$ \\
\hline Zhao et al. [7] & $\begin{array}{l}\text { Effective area was calculated } \\
\text { assuming uniform compression } \\
\text { at elevated temperatures }\end{array}$ & $\begin{array}{c}\text { Effective area was calculated } \\
\text { assuming pure bending at } \\
\text { elevated temperatures }\end{array}$ \\
\hline
\end{tabular}


Table 3: Comparison of Previous Fire Design Rules

\begin{tabular}{|c|c|c|c|c|c|c|c|}
\hline $\begin{array}{c}\text { Fire Design } \\
\text { Rules }\end{array}$ & $\begin{array}{c}\text { Klippstein } \\
\text { [1] }\end{array}$ & $\begin{array}{l}\text { Gerlich et } \\
\text { al. [2] }\end{array}$ & Ranby [3] & Kaitila [5] & $\begin{array}{l}\text { Feng and } \\
\text { Wang [6] }\end{array}$ & $\begin{array}{l}\text { Feng and } \\
\text { Wang [6] }\end{array}$ & Zhao et al. [7] \\
\hline $\begin{array}{l}\text { Standard } \\
\text { Used }\end{array}$ & AISI & AISI & $\begin{array}{c}\text { EC3 } \\
\text { Part } 1.3\end{array}$ & $\begin{array}{c}\text { EC3 } \\
\text { Part } 1.3\end{array}$ & $\begin{array}{c}\text { EC3 } \\
\text { Part } 1.2\end{array}$ & $\begin{array}{c}\text { EC3 } \\
\text { Part } 1.3\end{array}$ & $\begin{array}{c}\text { EC3 } \\
\text { Part } 1.3\end{array}$ \\
\hline Yield Stress & $\begin{array}{l}\text { Yield stress } \\
\text { at average } \\
\text { stud } \\
\text { temperature }\end{array}$ & $\begin{array}{l}\text { Yield stress } \\
\text { at cold } \\
\text { flange } \\
\text { temperature }\end{array}$ & $\begin{array}{l}\text { Yield stress } \\
\text { at average } \\
\text { stud } \\
\text { temperature }\end{array}$ & $\begin{array}{l}\text { Yield stress } \\
\text { at average } \\
\text { stud } \\
\text { temperature }\end{array}$ & $\begin{array}{c}\text { Weighted } \\
\text { average yield } \\
\text { stress at } \\
\text { elevated } \\
\text { temperature }\end{array}$ & $\begin{array}{c}\text { Weighted } \\
\text { average yield } \\
\text { stress at } \\
\text { elevated } \\
\text { temperature }\end{array}$ & $\begin{array}{c}\text { Weighted } \\
\text { average yield } \\
\text { stress at } \\
\text { elevated } \\
\text { temperature }\end{array}$ \\
\hline $\begin{array}{l}\text { Elastic } \\
\text { Modulus }\end{array}$ & $\begin{array}{c}\text { Elastic } \\
\text { modulus at } \\
\text { average stud } \\
\text { temperature }\end{array}$ & $\begin{array}{c}\text { Elastic } \\
\text { modulus at } \\
\text { average } \\
\text { stud } \\
\text { temperature }\end{array}$ & $\begin{array}{c}\text { Elastic } \\
\text { modulus at } \\
\text { average } \\
\text { stud } \\
\text { temperature }\end{array}$ & $\begin{array}{c}\text { Elastic } \\
\text { modulus at } \\
\text { average stud } \\
\text { temperature }\end{array}$ & $\begin{array}{c}\text { Weighted } \\
\text { average elastic } \\
\text { modulus at } \\
\text { elevated } \\
\text { temperature }\end{array}$ & $\begin{array}{c}\text { Weighted } \\
\text { average elastic } \\
\text { modulus at } \\
\text { elevated } \\
\text { temperature }\end{array}$ & $\begin{array}{c}\text { Weighted } \\
\text { average elastic } \\
\text { modulus at } \\
\text { elevated } \\
\text { temperature }\end{array}$ \\
\hline $\begin{array}{l}\text { Thermal } \\
\text { bowing }\end{array}$ & Considered & Considered & Considered & Considered & Considered & Considered & Considered \\
\hline $\begin{array}{c}\text { Magnification } \\
\text { effects }\end{array}$ & Considered & Considered & Considered & Considered & Considered & Considered & Considered \\
\hline $\begin{array}{c}\text { Neutral axis } \\
\text { shift }\end{array}$ & $\begin{array}{c}\text { Not } \\
\text { Considered }\end{array}$ & $\begin{array}{c}\text { Not } \\
\text { Considered }\end{array}$ & Considered & Considered & Considered & Considered & Considered \\
\hline $\begin{array}{l}\text { Capacity } \\
\text { Checks at }\end{array}$ & Mid-height & Mid-height & Mid-height & Mid-height & $\begin{array}{c}\text { Mid-height } \\
\text { and Stud End }\end{array}$ & $\begin{array}{l}\text { Mid-height } \\
\text { and Stud End }\end{array}$ & $\begin{array}{l}\text { Mid-height } \\
\text { and Stud End }\end{array}$ \\
\hline
\end{tabular}


Table 4: Failure Times Predicted by FEA and the Previous Fire Design Rules for Load Ratio of 0.2

\begin{tabular}{|c|c|c|c|c|c|c|c|c|c|c|c|c|}
\hline \multirow[b]{2}{*}{ Test } & \multirow[b]{2}{*}{ Configuration } & \multirow[b]{2}{*}{ Insulation } & \multicolumn{10}{|c|}{ Failure Time (min.) } \\
\hline & & & Test & FEA & $\begin{array}{c}\text { Klippstein } \\
\text { [1] }\end{array}$ & $\begin{array}{l}\text { Gerlich } \\
\text { et al. } \\
\text { [2] }\end{array}$ & $\begin{array}{c}\text { Ranby } \\
\text { [3] }\end{array}$ & $\begin{array}{c}\text { Kaitila } \\
\text { [5] }\end{array}$ & $\begin{array}{c}\text { Kaitila } \\
\text { [5] } \\
\text { NU }\end{array}$ & $\begin{array}{l}\text { Feng and } \\
\text { Wang [6] } \\
\text { EC3 P1.2 }\end{array}$ & $\begin{array}{l}\text { Feng and } \\
\text { Wang [6] } \\
\text { EC3 P1.3 }\end{array}$ & $\begin{array}{c}\text { Zhao et al. } \\
\text { [7] }\end{array}$ \\
\hline 1 & 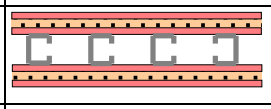 & $\begin{array}{l}\text { Glass } \\
\text { Fibre }\end{array}$ & 118 & 115 & - & 120 & 117 & 114 & 117 & 116 & 118 & 119 \\
\hline 2 & 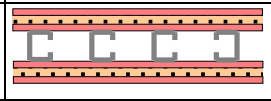 & $\begin{array}{l}\text { Glass } \\
\text { Fibre }\end{array}$ & - & 116 & - & 125 & 119 & 115 & 117 & 118 & 119 & 121 \\
\hline 3 & 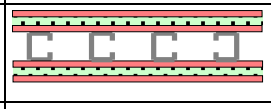 & $\begin{array}{l}\text { Rock } \\
\text { Fibre } \\
\end{array}$ & - & 143 & - & 144 & 139 & 136 & 138 & 139 & 139 & 141 \\
\hline $1 *$ & $\left.\begin{array}{lllll} & 5 & 5 & 1\end{array}\right]$ & None & 53 & 53 & - & 56 & 55 & 51 & 55 & 55 & 56 & 56 \\
\hline $2 *$ & 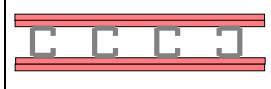 & None & 111 & 115 & - & 122 & 116 & 113 & 116 & 117 & 117 & 119 \\
\hline $3 *$ & Q & $\begin{array}{l}\text { Glass } \\
\text { Fibre }\end{array}$ & 101 & 100 & - & 105 & 105 & 96 & 102 & 102 & 103 & 107 \\
\hline $4^{*}$ & 1 $\because \cdots \because 6$ & $\begin{array}{l}\text { Rock } \\
\text { Fibre } \\
\end{array}$ & 107 & 105 & - & - & 116 & 99 & 109 & 109 & 110 & 120 \\
\hline $5^{*}$ & $-\because \cdots \cdots$ & $\begin{array}{l}\text { Cellulose } \\
\text { Fibre }\end{array}$ & 110 & 109 & - & - & 112 & 107 & 110 & 113 & 111 & 114 \\
\hline $6^{*}$ & 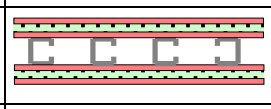 & $\begin{array}{l}\text { Rock } \\
\text { Fibre } \\
\end{array}$ & $136^{\#}$ & 154 & - & 155 & 152 & 149 & 152 & 153 & 155 & 154 \\
\hline $7^{*}$ & $\mathrm{CLC}$ & $\begin{array}{c}\text { Cellulose } \\
\text { Fibre }\end{array}$ & 124 & 129 & - & 133 & 130 & 126 & 129 & 130 & 131 & 132 \\
\hline
\end{tabular}

Tests 1 - 3 conducted by Gunalan [9]; Tests 1* - 7* conducted by Kolarkar [10]; ( \# ) - Earlier failure time due to lack of space for thermal expansion; (U) - Uniform temperature method; (NU) - Non-uniform temperature method; Tests 1 and $1 *-7^{*}$ were conducted under a load ratio of 0.2 ; Tests 2 and 3 were conducted under a load ratio of 0.4 
Table 5: Failure Times Predicted by FEA and the Previous Fire Design Rules for Load Ratio of 0.4

\begin{tabular}{|c|c|c|c|c|c|c|c|c|c|c|c|c|}
\hline \multirow[b]{2}{*}{ Test } & \multirow[b]{2}{*}{ Configuration } & \multirow[b]{2}{*}{ Insulation } & \multicolumn{10}{|c|}{ Failure Time (min.) } \\
\hline & & & Test & FEA & $\begin{array}{l}\text { Klippstein } \\
{[1]}\end{array}$ & $\begin{array}{l}\text { Gerlich } \\
\text { et al. } \\
\text { [2] }\end{array}$ & $\begin{array}{c}\text { Ranby } \\
\text { [3] }\end{array}$ & $\begin{array}{c}\text { Kaitila } \\
\text { [5] } \\
\text { U }\end{array}$ & $\begin{array}{c}\text { Kaitila } \\
\text { [5] } \\
\text { NU }\end{array}$ & $\begin{array}{l}\text { Feng and } \\
\text { Wang [6] } \\
\text { EC3 P1.2 }\end{array}$ & $\begin{array}{l}\text { Feng and } \\
\text { Wang [6] } \\
\text { EC3 P1.3 }\end{array}$ & $\begin{array}{c}\text { Zhao et al. } \\
\text { [7] }\end{array}$ \\
\hline 1 & \begin{tabular}{|l|l|l|l|} 
& \\
\end{tabular} & $\begin{array}{l}\text { Glass } \\
\text { Fibre }\end{array}$ & - & 109 & 108 & 111 & 108 & 108 & 107 & 108 & 107 & 109 \\
\hline 2 & 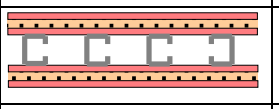 & $\begin{array}{l}\text { Glass } \\
\text { Fibre }\end{array}$ & 108 & 110 & - & 113 & 110 & 110 & 109 & 111 & 109 & 111 \\
\hline 3 & 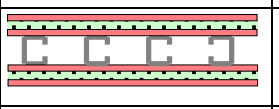 & $\begin{array}{l}\text { Rock } \\
\text { Fibre }\end{array}$ & 134 & 131 & 127 & 134 & 130 & 130 & 128 & 132 & 127 & 132 \\
\hline $1^{*}$ & 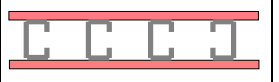 & None & - & 42 & 44 & 48 & 43 & 43 & 41 & 45 & 40 & 45 \\
\hline $2^{*}$ & 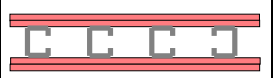 & None & - & 107 & 105 & 109 & 105 & 106 & 105 & 107 & 104 & 108 \\
\hline $3 *$ & A & $\begin{array}{l}\text { Glass } \\
\text { Fibre }\end{array}$ & - & 88 & 100 & 90 & 92 & 90 & 88 & 91 & 87 & 92 \\
\hline $4^{*}$ & : $\because \cdots$ & $\begin{array}{l}\text { Rock } \\
\text { Fibre }\end{array}$ & - & 91 & - & 99 & 95 & 93 & 91 & 94 & 89 & 96 \\
\hline $5 *$ & a $\because \cdots \cdots$ & $\begin{array}{l}\text { Cellulose } \\
\text { Fibre }\end{array}$ & - & 101 & 103 & 107 & 104 & 103 & 102 & 104 & 100 & 104 \\
\hline $6^{*}$ & $\begin{array}{ll}\mathrm{L} \\
\mathrm{C}\end{array}$ & $\begin{array}{l}\text { Rock } \\
\text { Fibre }\end{array}$ & - & 137 & - & 138 & 134 & 135 & 133 & 137 & 132 & 138 \\
\hline $7 *$ & $\begin{array}{lll}+C \\
\end{array}$ & $\begin{array}{l}\text { Cellulose } \\
\text { Fibre }\end{array}$ & - & 119 & 117 & 121 & 117 & 117 & 116 & 119 & 115 & 119 \\
\hline
\end{tabular}

Tests 1 - 3 conducted by Gunalan [9]; Tests 1* - 7* conducted by Kolarkar [10]; ( \# ) - Earlier failure time due to lack of space for thermal expansion; (U) - Uniform temperature method; (NU) - Non-uniform temperature method; Tests 1 and $1 *-7^{*}$ were conducted under a load ratio of 0.2 ; Tests 2 and 3 were conducted under a load ratio of 0.4 
Table 6: Failure Times Predicted by FEA and the Previous Fire Design Rules for Load Ratio of 0.7

\begin{tabular}{|c|c|c|c|c|c|c|c|c|c|c|c|c|}
\hline \multirow[b]{2}{*}{ Test } & \multirow[b]{2}{*}{ Configuration } & \multirow[b]{2}{*}{ Insulation } & \multicolumn{10}{|c|}{ Failure Time (min.) } \\
\hline & & & Test & FEA & $\begin{array}{c}\text { Klippstein } \\
{[1]}\end{array}$ & $\begin{array}{c}\text { Gerlich } \\
\text { et al. } \\
{[2]}\end{array}$ & $\begin{array}{c}\text { Ranby } \\
\text { [3] }\end{array}$ & $\begin{array}{c}\text { Kaitila } \\
\text { [5] } \\
\text { U } \\
\end{array}$ & $\begin{array}{c}\text { Kaitila } \\
\text { [5] } \\
\text { NU }\end{array}$ & $\begin{array}{l}\text { Feng and } \\
\text { Wang [6] } \\
\text { EC3 P1.2 }\end{array}$ & $\begin{array}{l}\text { Feng and } \\
\text { Wang [6] } \\
\text { EC3 P1.3 }\end{array}$ & $\begin{array}{c}\text { Zhao et al. } \\
\text { [7] }\end{array}$ \\
\hline 1 & 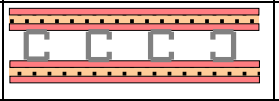 & $\begin{array}{l}\text { Glass } \\
\text { Fibre }\end{array}$ & - & 72 & 80 & 79 & 76 & 91 & 74 & 82 & 75 & 83 \\
\hline 2 & 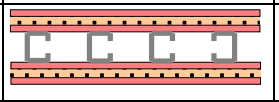 & $\begin{array}{l}\text { Glass } \\
\text { Fibre }\end{array}$ & - & 85 & 84 & 89 & 87 & 100 & 86 & 93 & 85 & 93 \\
\hline 3 & $\frac{1}{1}$ & $\begin{array}{l}\text { Rock } \\
\text { Fibre } \\
\end{array}$ & - & 95 & 99 & 98 & 97 & 113 & 96 & 101 & 96 & 103 \\
\hline $1^{*}$ & $\begin{array}{lllll} & & & & \\
\end{array}$ & None & - & 20 & 26 & 23 & 21 & 32 & 21 & 24 & 22 & 26 \\
\hline $2 *$ & 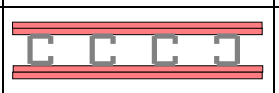 & None & - & 63 & 67 & 69 & 66 & 83 & 64 & 75 & 64 & 74 \\
\hline $3 *$ & $1-\cdots \because \cdots$ & $\begin{array}{l}\text { Glass } \\
\text { Fibre }\end{array}$ & - & 62 & 63 & 65 & 63 & 77 & 62 & 65 & 63 & 68 \\
\hline $4 *$ & a & $\begin{array}{l}\text { Rock } \\
\text { Fibre } \\
\end{array}$ & - & 64 & 63 & 65 & 64 & 79 & 63 & 66 & 64 & 69 \\
\hline $5 *$ & 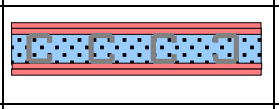 & $\begin{array}{l}\text { Cellulose } \\
\text { Fibre }\end{array}$ & - & 64 & 64 & 67 & 64 & 82 & 63 & 68 & 64 & 72 \\
\hline $6^{*}$ & $\mathrm{CLC}$ & $\begin{array}{l}\text { Rock } \\
\text { Fibre }\end{array}$ & - & 99 & 96 & 102 & 101 & 114 & 100 & 105 & 100 & 105 \\
\hline $7^{*}$ & $\begin{array}{c}2 \mathrm{C} \\
\mathrm{C} C \mathrm{C}\end{array}$ & $\begin{array}{l}\text { Cellulose } \\
\text { Fibre }\end{array}$ & - & 87 & 92 & 91 & 89 & 104 & 88 & 93 & 89 & 95 \\
\hline
\end{tabular}

Tests 1 - 3 conducted by Gunalan [9]; Tests $1^{*}$ - 7* conducted by Kolarkar [10]; ( \# ) - Earlier failure time due to lack of space for thermal expansion; (U) - Uniform temperature method; (NU) - Non-uniform temperature method; Tests 1 and $1 *-7^{*}$ were conducted under a load ratio of 0.2 ; Tests 2 and 3 were conducted under a load ratio of 0.4 
